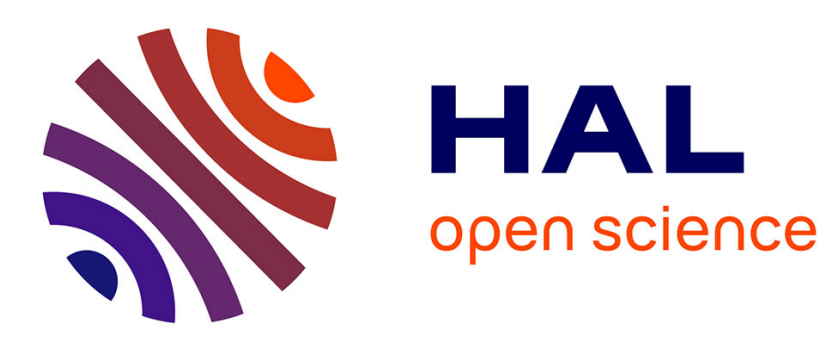

\title{
Induced polarization of volcanic rocks. 5. Imaging the temperature field of shield volcanoes
}

\author{
A Revil, Y Qi, A Ghorbani, M Gresse, D M Thomas
}

\section{To cite this version:}

A Revil, Y Qi, A Ghorbani, M Gresse, D M Thomas. Induced polarization of volcanic rocks. 5. Imaging the temperature field of shield volcanoes. Geophysical Journal International, 2021, 225, pp.1492 - 1509. 10.1093/gji/ggab039 . hal-03226981

\section{HAL Id: hal-03226981 \\ https://hal.science/hal-03226981}

Submitted on 16 May 2021

HAL is a multi-disciplinary open access archive for the deposit and dissemination of scientific research documents, whether they are published or not. The documents may come from teaching and research institutions in France or abroad, or from public or private research centers.
L'archive ouverte pluridisciplinaire HAL, est destinée au dépôt et à la diffusion de documents scientifiques de niveau recherche, publiés ou non, émanant des établissements d'enseignement et de recherche français ou étrangers, des laboratoires publics ou privés. 


\title{
Induced polarization of volcanic rocks. 5. Imaging the temperature field of shield volcanoes
}

\author{
A. Revil, ${ }^{1}$ Y. Qi,${ }^{1}$ A. Ghorbani, ${ }^{2}$ M. Gresse ${ }^{3}$ and D.M. Thomas ${ }^{4}$ \\ ${ }^{1}$ Univ. Grenoble Alpes, Univ. Savoie Mont-Blanc, CNRS, UMR CNRS 5204, EDYTEM, 73370 Le Bourget du Lac, France. E-mail: andre.revil@univ-smb.fr \\ ${ }^{2}$ Department of Mining and Metallurgical Engineering, Yazd University, Yazd, Iran \\ ${ }^{3}$ Earthquake Research Institute, University of Tokyo, Tokyo, Japan \\ ${ }^{4}$ University of Hawai'i at Manoa, Hawai'i Institute of Geophysics and Planetology, Honolulu, HI, USA
}

Accepted 2021 January 25. Received 2021 January 23; in original form 2020 October 29

\begin{abstract}
SUMMAR Y
Kilauea is an active shield volcano located in Hawai' $i$. An induced polarization survey was performed in 2015 at the scale of the caldera. The data were acquired with a $2.5 \mathrm{~km}$ cable with 64 electrodes and a spacing of $40 \mathrm{~m}$ between the electrodes. A total of 6210 measurements were performed. The apparent chargeability data were inverted using a least square technique to obtain a chargeability tomogram. The normalized chargeability tomogram is obtained by multiplying cell-by-cell the chargeability by the conductivity. Once the conductivity and normalized chargeability tomograms are obtained, they are jointly interpreted using a dynamic Stern layer conduction/polarization model, which explains the low-frequency polarization spectra of volcanic rocks. This conductivity/polarization model is tested here on new laboratory experiments performed on 24 samples from a drill-hole located on the Kilauea East Rift Zone (Hole SOH-2). We show that for Kilauea, the ratio between the normalized chargeability and the conductivity is equal to a dimensionless number $R=0.10 \pm 0.02$ proving that the conductivity and the normalized chargeability are both controlled by the alteration products of the volcanic rocks with a minor role of magnetite except close to the ground surface. In turn, the degree of alteration is controlled by temperature and therefore normalized chargeability and electrical conductivity can both be used as a non-intrusive temperature sensor. This approach is then applied to the field data. Meaningful temperature tomograms can be produced from both electrical conductivity and normalized chargeability tomograms.
\end{abstract}

Key words: Electrical properties; Hydrothermal systems; Electrical resistivity tomography (ERT).

\section{INTRODUCTION}

Developing non-intrusive temperature sensors for volcanoes is of paramount importance to understand their plumbing system and to monitor their activity (Frolova et al. 2010). Induced polarization is a geophysical technique that can be used to image the ability of rocks to reversibly store electrical charges (Olhoeft 1985). In volcanic rocks, this property seems to be controlled by the polarization of the Stern layer, the inner component of the electrical double layer coating non-metallic grains at the nano-scale (Revil et al. 2019). The magnitude of polarization is very sensitive to the cation exchange capacity (CEC) of the porous material (Vinegar \& Waxman 1984). In addition to the polarization of non-metallic grains, metallic grains such as pyrite and magnetite can be polarized (see Pelton et al. 1978; Misra et al. 2016a,b).

For non-metallic particles, the polarization of a rock is usually dominated by the polarization of alumino-silicates (clays and zeolites, see Revil et al. 2018). For semi-conductors (magnetite, pyrite and similarly metallic particles), the polarization is controlled by the volumetric amount of metallic particles (Wong 1979; Revil et al. $2015 \mathrm{a}, \mathrm{b})$. In addition, alteration of volcanic rocks is responsible for the disappearance of magnetite and then the metallic contribution to polarization rapidly becomes vanishingly small at depth (Revil et al. 2019). A total understanding of the polarization of volcanic rocks requires therefore a theory combining the background polarization of the non-metallic grains as well as the polarization and conduction effects associated with the presence of magnetite and pyrite.

In this paper, we argue that since alteration of volcanic rocks is essentially a temperature-controlled process (Browne 1978; Frolova et al. 2010), polarization of rocks could be used as a non-intrusive temperature sensor. In order to demonstrate this point, we gather a set of new experimental data using 24 core samples from a deep well (Hole SOH-2) located at Kilauea volcano in Hawai' $i$ and where alteration has taken place in the temperature range $100-350{ }^{\circ} \mathrm{C}$ (Figs 1 and 2). We develop a new polarization model of volcanic 


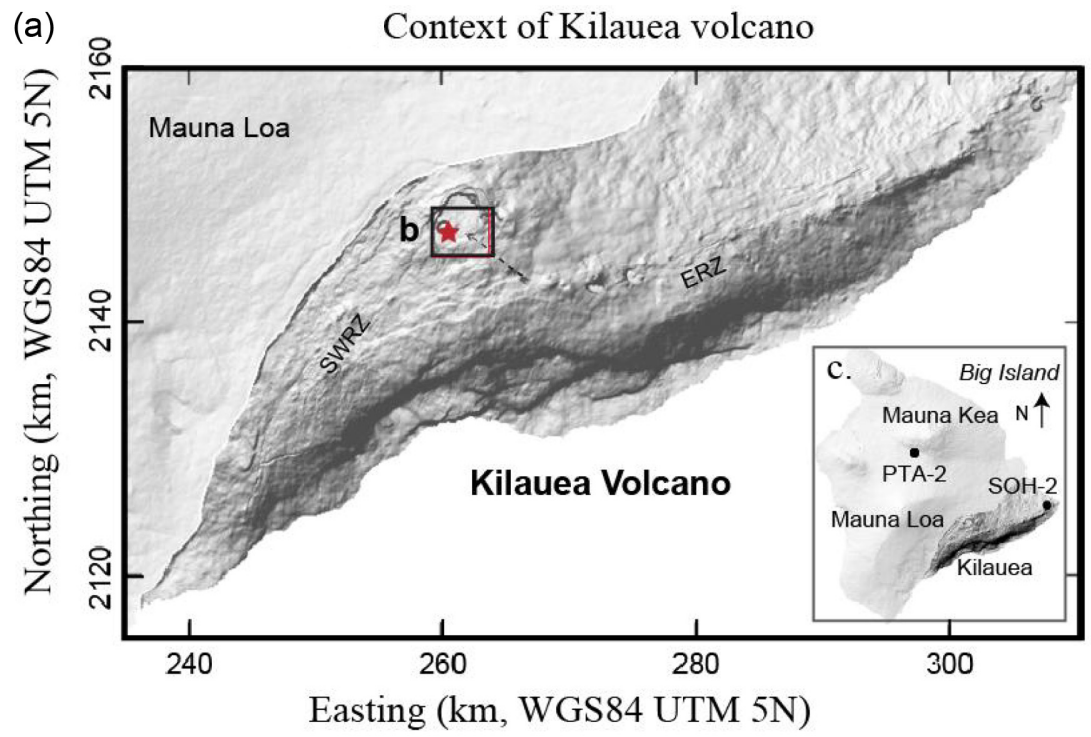

(b) Context of Halema uma 'u pit crater

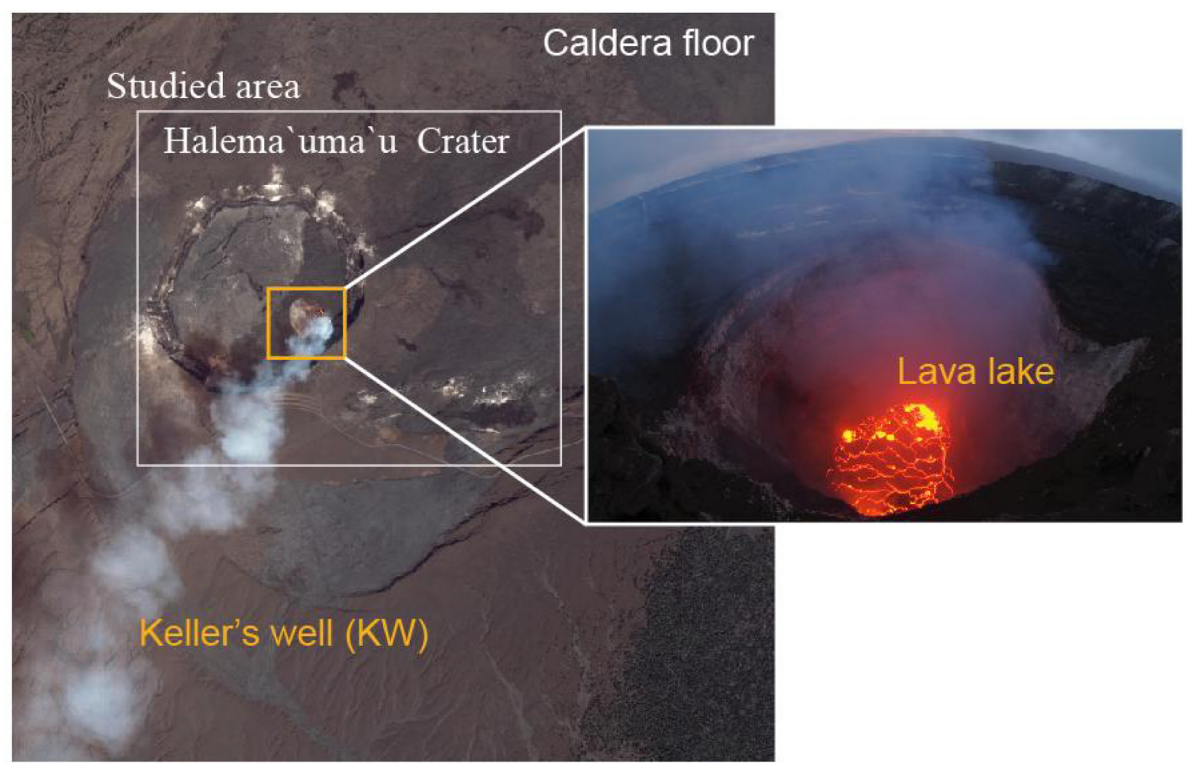

Figure 1. Kỉlauea volcano (Hawai'i (USA). (a) Kîlauea volcano. ER stands for the East Rift Zone and SWRZ for the SouthWest Rift Zone. (b) Summit caldera and the Halema 'uma 'u pit crater. Keller's well K-W is shown. (c) Position of wells PTA-2 in the Humu'ula saddle region between Mauna Kea and Mauna Loa volcanoes and well SOH-2 in the Kapoho area in the Eastern part of Kilauea volcano.

rocks including the polarization of the background material as well as the polarization of the metallic particles. These new concepts are then applied to Kilauea volcano in Hawai'i. Kilauea was chosen because several drill holes are available with cores that can be used to assess the relationship between alteration (using the CEC as proxy) and the normalized chargeability, one of the main properties obtained in an induced polarization survey.

\section{INDUCED POLARIZATION OF VOLCANIC ROCKS}

\subsection{A general model}

In our previous papers, we developed a theory of induced polarization for volcanic rocks without metallic particles (Revil et al. $2017 \mathrm{a}, \mathrm{b}$ ) but a general model including the polarization of metallic and non-metallic grains was still missing to date. Assuming a linear, time-invariant, isotropic volcanic rock, an Ohm's law including the low-frequency part of the Maxwell-Wagner effect and the polarization of the electrical double layer associated with electrochemical potential gradients can be written (Revil et al. 2017c),

$\mathbf{J}=\sigma *(\omega) \mathbf{E}$,

$\sigma *(\omega)=\sigma^{\prime}+i \sigma^{\prime \prime}$

where $\mathbf{J}$ and $\mathbf{E}$ denote the total current density and electrical field, respectively, $\sigma *(\omega)$ the complex conductivity, $\sigma^{\prime}\left(>0\right.$, in $\left.\mathrm{S} \mathrm{m}^{-1}\right)$ characterizes electromigration and $\sigma^{\prime \prime}\left(<0\right.$, in $\left.\mathrm{S} \mathrm{m}^{-1}\right)$ characterizes polarization. They correspond to the in-phase and quadrature conductivity of the rock, $i$ denotes the pure imaginary number $\left(i^{2}=\right.$ 


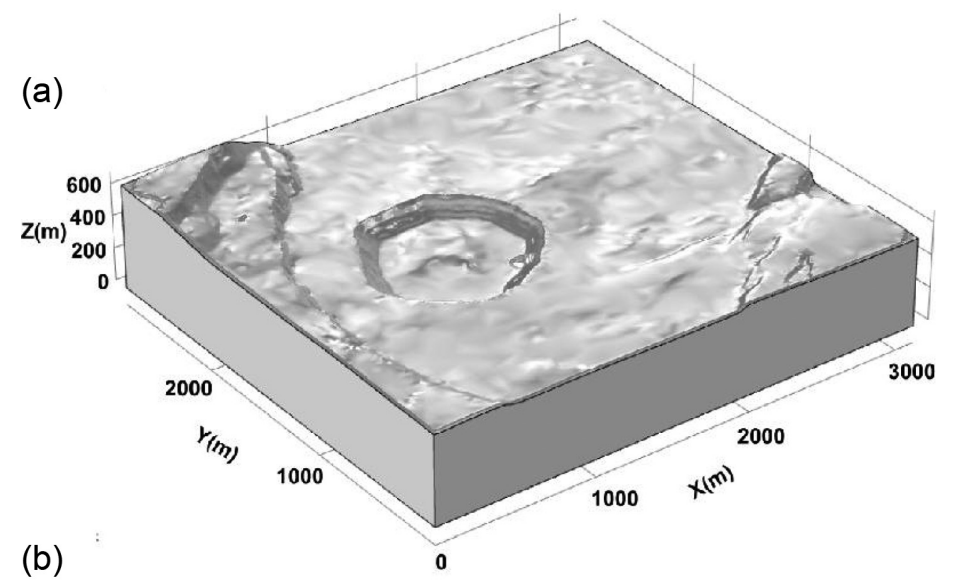

(b)

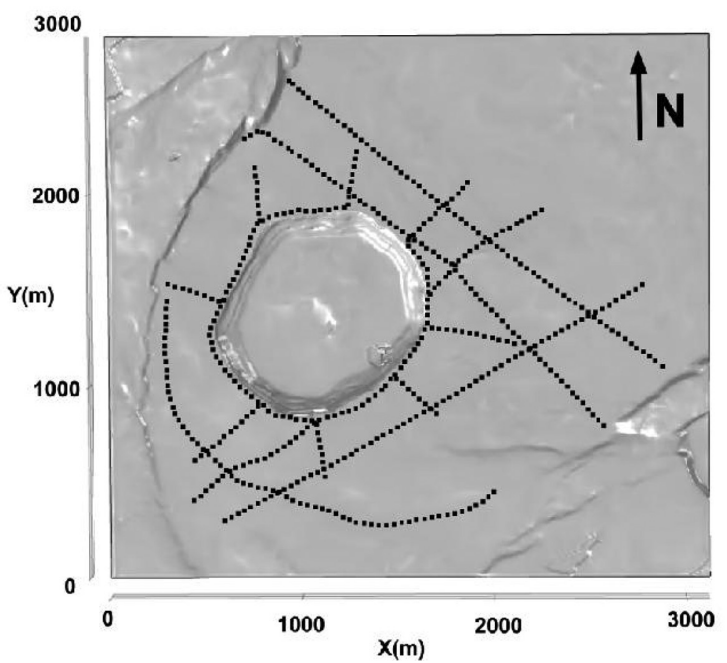

Figure 2. Position of the geophysical profiles on Kîlauea volcano. (a) Topography of the test site around the Halema uma 'u pit crater. (b) Location of the profiles. We use a cable of $2.5 \mathrm{~km}$ (Wenner- $\alpha$ array, electrode spacing of $40 \mathrm{~m}, 64$ stainless electrodes steel electrodes). A total of 6210 measurements were performed and used for the inversion.

$-1), \omega$ the pulsation frequency $\left(\operatorname{rad~s}^{-1}\right), h(\tau)$ denotes the normalized probability density for the distribution of the relaxation times and $\varepsilon_{\infty}$ a dielectric constant of the medium associated with the low-frequency part of the Maxwell-Wagner polarization.

For volcanic rocks, we assume that there are two main polarization processes corresponding to (1) the inner polarization of the semi-conductors (magnetite and pyrite, mechanism 1, Fig. 3d) and (2) the polarization of the double layer of non-metallic grains (especially the clays and zeolites resulting from alteration, mechanism 2, Fig. 3c). This yields the following form of the complex conductivity,

$\sigma *=\sigma_{\infty}\left(1-\frac{M_{1}}{1+\left(i \omega \tau_{1}\right)^{c_{1}}}-\frac{M_{2}}{1+\left(i \omega \tau_{2}\right)^{c_{2}}}\right)$,

$\sigma_{\infty}=\sigma_{1}^{\infty}+\sigma_{2}^{\infty}$,

$\sigma_{0}=\sigma_{\infty}\left(1-M_{1}-M_{2}\right)$,

where $M_{1}$ and $M_{2}$ are the chargeabilities (dimensionless), $c_{1}$ and $c_{2}$ are the two Cole-Cole exponents (dimensionless) and $\tau_{1}$ and $\tau_{2}$ are the (relaxation) time constants (expressed in s). If the total chargeability is defined by $M=\left(\sigma_{\infty}-\sigma_{0}\right) / \sigma_{\infty}$, we have $M=M_{1}+M_{2}$.
We do not focus on the relaxation times in this paper and therefore we will try to provide their expressions.

\subsection{The contribution associated with the background}

The instantaneous conductivity is the conductivity of the material just after the application of an electrical field (see Fig. 2, highfrequency asymptotic conductivity in frequency-domain induced polarization). The dc (direct current) or stationary conductivity denotes a smaller conductivity including the effect of charge carrier blockage responsible for polarization (Fig. 2). Using a volumeaveraging approach, Revil (2013) obtained the following expressions for the high and low frequency conductivities of the background material (i.e. for the instantaneous conductivity and dc conductivity of the background material, see Fig. 2),

$\sigma_{2}^{\infty}=\frac{1}{F} \sigma_{w}+\left(\frac{1}{F \phi}\right) \rho_{g} B \mathrm{CEC}$,

$\sigma_{2}^{0}=\frac{1}{F} \sigma_{w}+\left(\frac{1}{F \phi}\right) \rho_{g}(B-\lambda) \mathrm{CEC}$, 
(a) Background

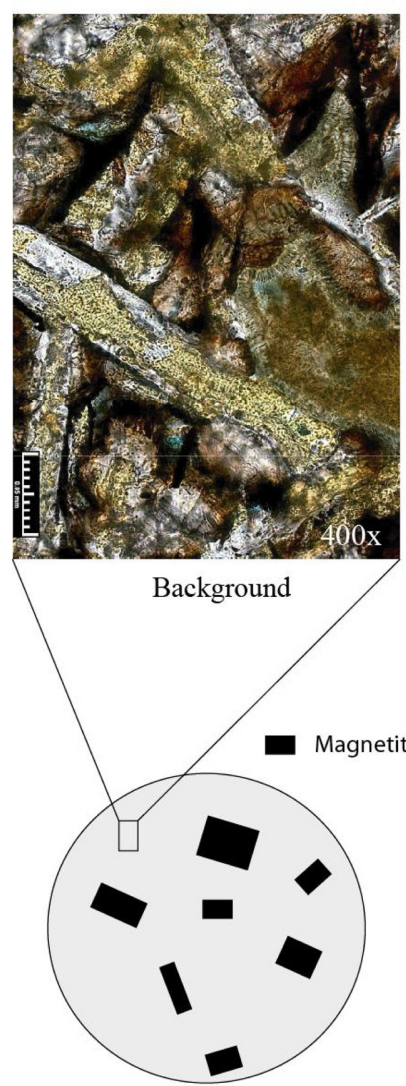

(b) Volcanic rock

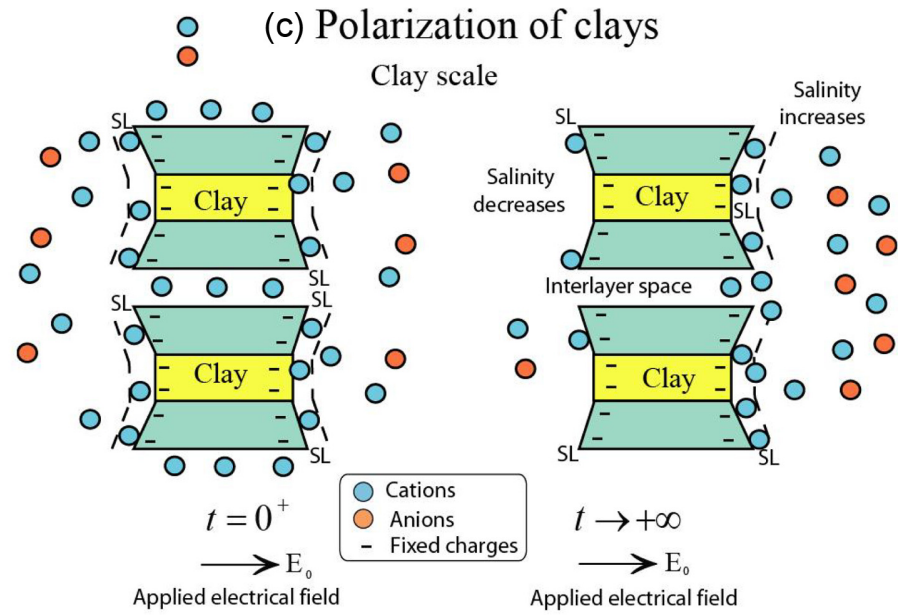

$\sigma=\sigma_{\infty}$

$\sigma=\sigma_{0}=\sigma_{\infty}(1-M)$

Instantaneous conductivity

Not-polarized

Direct Current (DC) conductivity

Polarized

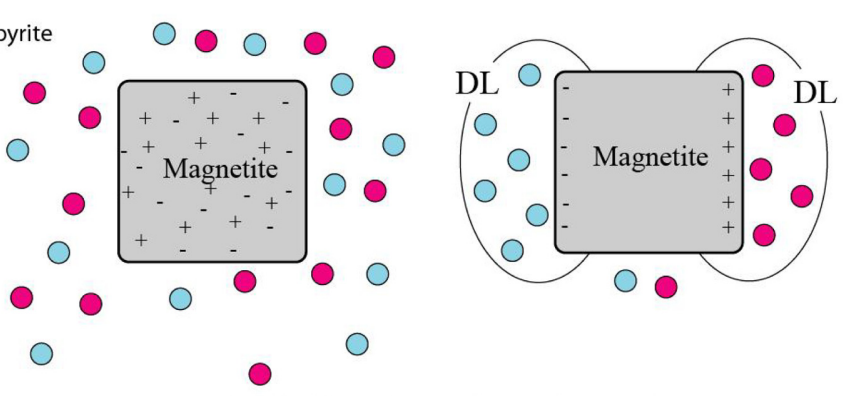

(d) Polarization of semi-conductors

Figure 3. Polarization of a volcanic rock. (a) Volcanic rock sample submitted to an applied electrical field $\mathbf{E}_{0}$. (b) A volcanic rock can be modelled as a mixture between a background composed of the non-metallic grains (filled with some pore water) plus immersed semi-conductors such as magnetite and/or pyrite. (c) The grains associated with the alteration (clays and zeolites) are surrounded by an electrical double layer. Just after the application of the electrical field (at $t=0+$ ), all the charge carriers are mobile and contribute to surface conduction defining the instantaneous conductivity $\sigma_{\infty}$. When the electrical field has been applied for a long time, these grains get fully polarized. The charge carriers associated with the polarization do not contribute to conduction. This state defines the direct current (dc) conductivity $\sigma_{0}$. SL stands for the Stern Layer while $M$ (dimensionless) corresponds to the chargeability. (d) Polarization of a metallic particle (pyrite or magnetite). The polarization is essentially due to the polarization of the particle itself (DL stands for diffuse layer).

where the index $\infty$ is used for the instantaneous (high frequency) property while the index 0 is kept for the dc property (zero frequency). For partial saturations, $1 / F$ should be replaced by $\theta \mathrm{m}$ and the porosity $\phi$ by $\theta$ where $\theta$ denotes the volume fraction of water in the rock (product of the saturation by the porosity). In these equations, $\sigma_{w}$ (in $\mathrm{S} \mathrm{m}^{-1}$ ) denotes the pore water conductivity (which depends on both salinity and temperature), $F$ (dimensionless) the intrinsic formation factor related to the connected porosity $\phi$ (dimensionless) by the first Archie's law $F=\phi^{-\mathrm{m}}$ where $m$ (dimensionless) is called the first Archie exponent or porosity exponent (Archie 1942), $\rho_{g}$ is the grain density (in $\mathrm{kg} \mathrm{m}^{-3}$, usually $\rho_{g} \approx 2900 \mathrm{~kg} \mathrm{~m}^{-3}$ for volcanic rocks, and CEC denotes the CEC (in $\mathrm{C} \mathrm{kg}^{-1}$ and often expressed in meq/100 $\mathrm{g}$ with 1 meq $/ 100 \mathrm{~g}=963.20 \mathrm{C} \mathrm{kg}^{-1}$ ). The $\mathrm{CEC}$ is mainly sensitive to the clay type (e.g. kaolinite, illite, smectite) and the weight fraction of these clay minerals in the rock (Waxman \& Smits 1968) and therefore, for volcanic rocks, to alteration. In eqs (6) and (7), the quantity $B$ (expressed in $\mathrm{m}^{2} \mathrm{~s}^{-1} \mathrm{~V}^{-1}$ ) denotes the apparent mobility of the counterions for surface conduction while the quantity $\lambda$ (expressed in $\mathrm{m}^{2} \mathrm{~s}^{-1} \mathrm{~V}^{-1}$ ) denotes the apparent mobility of the counterions for the polarization associated with the quadrature conductivity (see Revil et al. 2017a, and references therein). A dimensionless number $\mathrm{R}$ is also introduced as,

$\mathrm{R}=\frac{\lambda}{B}$,

(see Revil et al. 2017a for further explanations). From our previous studies (e.g. Ghorbani et al. 2018), we have $B\left(\mathrm{Na}^{+}, 25^{\circ} \mathrm{C}\right)=$ $3.1 \pm 0.3 \times 10^{-9} \mathrm{~m}^{-2} \mathrm{~s}^{-1} \mathrm{~V}^{-1}$ and $\lambda\left(\mathrm{Na}^{+}, 25^{\circ} \mathrm{C}\right)=3.0 \pm 0.7 \times$ $10^{-10} \mathrm{~m}^{-2} \mathrm{~s}^{-1} \mathrm{~V}^{-1}$, and these two mobilities have the same temperature dependence (Ghorbani et al. 2018). These two quantities have been determined using large data sets of rock samples (including hundreds of core samples). It follows that the dimensionless number $R$ is typically around $0.10 \pm 0.02$ (independent of the temperature and saturation, Revil et al. 2018).

Since the chargeability is given by $M_{2}=\left(\sigma_{2}^{\infty}-\sigma_{2}^{0}\right) / \sigma_{2}^{\infty}$, we obtain the following expression of the chargeability of the background,

$M_{2}=\frac{\rho_{g} \lambda \mathrm{CEC}}{\phi \sigma_{w}+\rho_{g} B \mathrm{CEC}}$. 
Table 1. Petrophysical properties of the core samples from Well SOH-2. The $\mathrm{pH}$ is the equilibrium $\mathrm{pH}$ of the solution for the CEC measurements. CEC denotes the cation exchange capacity, $S_{s p}$ the specific surface area of the core samples. The relative error on the $\mathrm{CEC}$ and specific surface area measurements is typically around 1 per cent. MPB: Massive pillow basalt, PB: pillow basalt, PR: pillow rubble, VPU Vesicular pillow unit, AH Altered hyaloclastite (accumulations of volcanic glass shards), BD brecciated dike, VD vesicular dike, AP Altered pillow, AD avesicular dike, SVP sparsely vesicular pillow, SVD sparsely vesicular dike, and PP Picritic pillow. The quantity $\mathrm{T}\left({ }^{\circ} \mathrm{C}\right)$ denotes the equilibrium temperature in Well SOH-2.

\begin{tabular}{|c|c|c|c|c|c|c|c|}
\hline Sample ID & Depth (m) & Description & Porosity $\phi(-)$ & $\mathrm{CEC}(\mathrm{meq} / 100 \mathrm{~g})$ & $\mathrm{pH}(-)$ & $S_{s p}$ BET $\left(\mathrm{m}^{2} \mathrm{~g}^{-1}\right)$ & $T\left({ }^{\circ} \mathrm{C}\right)$ \\
\hline S1 & 583.69 & MPB & 0.07 & 2.8200 & 8.6800 & 0.86 & 26 \\
\hline S2 & 600.76 & MPB & 0.04 & 3.6000 & 8.9900 & 1.21 & 27 \\
\hline S3 & 623.01 & PR & 0.02 & 2.3900 & 8.6600 & - & 28 \\
\hline S4 & 857.80 & $\mathrm{~PB}$ & 0.04 & 11.490 & - & 4.16 & 61 \\
\hline S5 & 1254.6 & VPU & 0.20 & 33.570 & - & 2.17 & 129 \\
\hline S6 & 1278.6 & $\mathrm{AH}^{\mathrm{a}}$ & 0.16 & 148.97 & 7.7100 & 13.0 & 135 \\
\hline S7 & 1353.2 & VPU & 0.22 & 40.170 & 7.3400 & 2.96 & 154 \\
\hline S8a & 1392.3 & $\mathrm{BD}$ & 0.19 & 106.92 & 7.3100 & 12.78 & 169 \\
\hline $\mathrm{S} 8 \mathrm{~b}$ & 1392.3 & $\mathrm{BD}$ & 0.15 & 106.92 & 7.8900 & 12.78 & 169 \\
\hline S9 & 1479.5 & $\mathrm{VD}^{\mathrm{b}}$ & 0.01 & 29.990 & 7.1700 & 1.75 & 206 \\
\hline S10 & 1501.1 & $\mathrm{AH}^{\mathrm{c}}$ & - & 213.90 & 7.0400 & 10.10 & 217 \\
\hline $\mathrm{S} 11$ & 1515.8 & $\mathrm{AP}^{\mathrm{d}}$ & 0.03 & 67.020 & 6.9200 & 5.08 & 221 \\
\hline $\mathrm{S} 12$ & 1542.7 & $\mathrm{AP}^{\mathrm{b}}$ & 0.14 & 98.500 & 9.1500 & 6.68 & 225 \\
\hline $\mathrm{S} 13$ & 1592.7 & $\mathrm{AH}$ & 0.05 & 74.430 & 8.4700 & 3.84 & 230 \\
\hline $\mathrm{S} 14$ & 1708.1 & $\mathrm{AD}$ & 0.01 & 11.520 & 8.1200 & 1.74 & 265 \\
\hline S15 & 1777.6 & SVP & 0.18 & 5.2300 & 8.3400 & 1.58 & 290 \\
\hline S16 & 1829.9 & VP & 0.13 & 3.1300 & 8.2400 & 2.55 & 300 \\
\hline S17 & 1887.2 & SVD & 0.06 & 11.590 & 8.2000 & 4.47 & 317 \\
\hline S18 & 1887.7 & $\mathrm{SVD}^{\mathrm{e}}$ & 0.06 & 13.100 & - & 2.94 & 317 \\
\hline S19 & 1967.5 & $\mathrm{AD}$ & 0.02 & 13.360 & - & 0.75 & 327 \\
\hline S20 & 2001.2 & $P P^{f}$ & 0.05 & 68.460 & 8.5800 & 4.10 & 340 \\
\hline S21 & 2051.3 & $\mathrm{BD}^{\mathrm{e}}$ & 0.04 & 42.950 & 8.2400 & 11.07 & 343 \\
\hline S22 & 2062.0 & $\mathrm{PP}^{\mathrm{e}}$ & - & 73.900 & 7.8900 & 13.01 & 348 \\
\hline S23 & 2071.9 & $\mathrm{PP}^{\mathrm{e}}$ & 0.09 & 24.430 & - & 18.44 & 350 \\
\hline
\end{tabular}

${ }^{\mathrm{a}}$ Completely altered to smectite clay (Nowack \& Evans 1991).

${ }^{\mathrm{b}}$ Vesicles filled with black clays (Nowack \& Evans 1991).

${ }^{\mathrm{c}}$ Entire unit is altered to smectite and brecciated to rubble (Nowack \& Evans 1991).

${ }^{\mathrm{d}}$ Altered towards smectite (Nowack \& Evans 1991).

${ }^{\text {e}}$ Presence of fractures and smectite and pyrite (Nowack \& Evans 1991).

${ }^{\mathrm{f}}$ Altered to smectite (Nowack \& Evans 1991).

This equation shows explicitly the dependence between the background chargeability $M_{2}\left(0 \leq M_{2} \leq 1\right)$, the pore water conductivity, and the CEC. We also have the property $M_{2} \leq$ $R \sim 0.10 \pm 0.02$. Therefore, the chargeability of the background material is generally quite small (less than 10 per cent or $100 \mathrm{mV} \mathrm{V}^{-1}$ ).

In this paper, we avoid having to treat the relaxation time distribution of the background by assuming that the distribution of the relaxation times associated with the polarization of the nonmetallic grains is broad enough to use a constant phase model (see Van Voorhis et al. 1973) instead of a Cole-Cole complex conductivity model. Considering the quadrature conductivity at the geometric mean of two frequencies $f_{1}$ and $f_{2}$ and the normalized chargeability defined as the difference between the in-phase conductivity at the frequency $f_{2}\left(>f_{1}\right)$ and the in-phase conductivity at the lower frequency $f_{1}$, we can connect the quadrature conductivity and the normalized chargeability with (Van Voorhis et al. 1973; Revil et al. 2017c)

$\sigma^{\prime \prime}\left(\sqrt{f_{1} f_{2}}\right) \approx-\frac{M_{n}\left(f_{1}, f_{2}\right)}{\alpha}$,

and $\alpha \approx(2 / \pi) \ln A$ and $A$ denotes the number of decades between $f_{1}$ and $f_{2}$ (for 3 decades, we have $A=10^{3}$ and $\alpha \approx 4.4$ ). If we further assume that all the relaxation times are contained inside 6 orders of magnitude, the largest value for $\alpha$ is $\alpha=8.8$ (using $\alpha \approx(2 / \pi) \ln A, 6$ orders of magnitude). We will proof-check these relationships in this paper. The normalized chargeability and the quadrature conductivity of the background (index 2) are given as,

$M_{n}^{2}=\left(\frac{1}{F \phi}\right) \rho_{g} \lambda \mathrm{CEC}$,

$\sigma_{2}^{\prime \prime} \approx-\left(\frac{1}{\alpha F \phi}\right) \rho_{g} \lambda \mathrm{CEC}$.

In the next section, we evaluate the polarization associated with the metallic particles.

\subsection{Semi-conductor contribution}

For a mixture of non-metallic grains, pore water and metallic grains, Revil et al. $(2015 \mathrm{a}, \mathrm{b})$ have demonstrated that the chargeability of the mixture $M(0 \leq M \leq 1)$ is given by

$M \approx \frac{9}{2} \varphi_{m}+M_{2}$,

where $\varphi_{m}\left(0 \leq \varphi_{m} \leq 1\right.$ dimensionless $)$ denotes the volume fraction of metallic particles in the medium. Eq. (13) is valid as long as $\varphi_{m} \leq$ 0.3 . In addition, the instantaneous and the steady state conductivities of the mixture are related to the instantaneous and steady state conductivities of the background material according to (Revil et al. 2015a)

$\sigma_{\infty}=\sigma_{2}^{\infty}\left(1+3 \varphi_{m}+\ldots\right)$, 

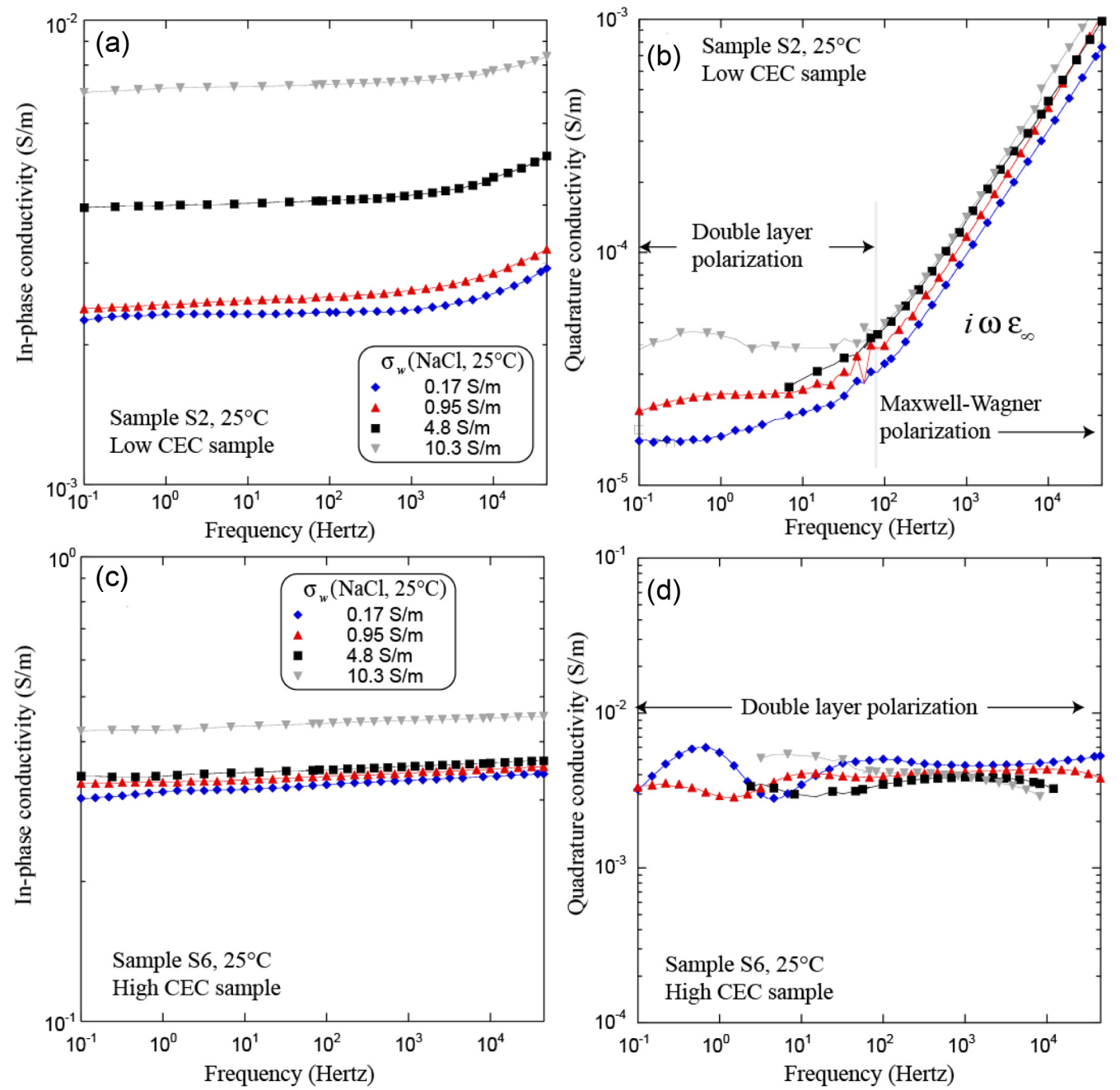

Figure 4. Complex conductivity spectra. (a) In-phase conductivity, Sample S2. (b) Quadrature conductivity, Sample S2. We can observe the Maxwell-Wagner (interfacial) polarization in the high frequency part of the quadrature conductivity spectra for the core samples with low CEC values (here above $100 \mathrm{Hertz}$ ). (c) In-phase conductivity, Sample S6. (d) Quadrature conductivity, Sample S6. The Maxwell-Wagner polarization cannot be observed in the quadrature conductivity spectra for the core samples with high CEC values since the polarization response is dominated by the double layer polarization and the Maxwell-Wagner polarization is therefore masked.

$\sigma_{0}=\sigma_{2}^{0}\left(1-\frac{3}{2} \varphi_{m}+\ldots\right)$

where $\sigma_{2}^{0}$ and $\sigma_{2}^{\infty}$ are defined through eqs (6) and (7). Following eqs (14) and (15), an amount of magnetite of 4 per cent has only a very minor effect on the conductivity of the mixture. We will see below that this is not the case for the quadrature conductivity. Using the definition of the total chargeability of the mixture and the chargeability together with eqs (14) and (15) and the expression of the chargeability of the background, eq. (9), we obtain,

$M_{1}=\frac{9}{2} \varphi_{m}$,

$\sigma_{1}^{\infty}=3 \varphi_{m} \sigma_{2}^{\infty}$

$\sigma_{1}^{0}=\sigma_{1}^{\infty}\left(1-\frac{9}{2} \varphi_{m}\right)=3 \varphi_{m}\left(1-\frac{9}{2} \varphi_{m}\right) \sigma_{2}^{\infty}$
We need now to obtain a description of the normalized chargeability and the quadrature conductivity of a volcanic rock. The normalized chargeability of the volcanic rock can be obtained as,

$M_{n}=M \sigma_{\infty}$

Using eqs (14) and (15), we obtain

$M_{n}=\sigma_{2}^{\infty}\left(\frac{9}{2} \varphi_{m}+M_{2}\right)\left(1+3 \varphi_{m}+\ldots\right)$

$M_{n}=\sigma_{2}^{\infty}\left[\frac{9}{2} \varphi_{m}+M_{2}\left(1+3 \varphi_{m}+\ldots\right)\right]$,

where we have neglected second order terms in $\varphi_{m}$. Using now eq. (6) for $\sigma_{2}^{\infty}$ and eq. (9) for $M_{2}$, we obtain after a few algebraic manipulations

$$
\begin{aligned}
M_{n}= & \frac{9}{2 F} \varphi_{m}\left(\sigma_{w}+\frac{\rho_{g}}{\phi}\left(\frac{2}{3} \lambda+B\right) \mathrm{CEC}\right) \\
& +\left(\frac{1}{F \phi}\right) \rho_{g} \lambda \mathrm{CEC} .
\end{aligned}
$$



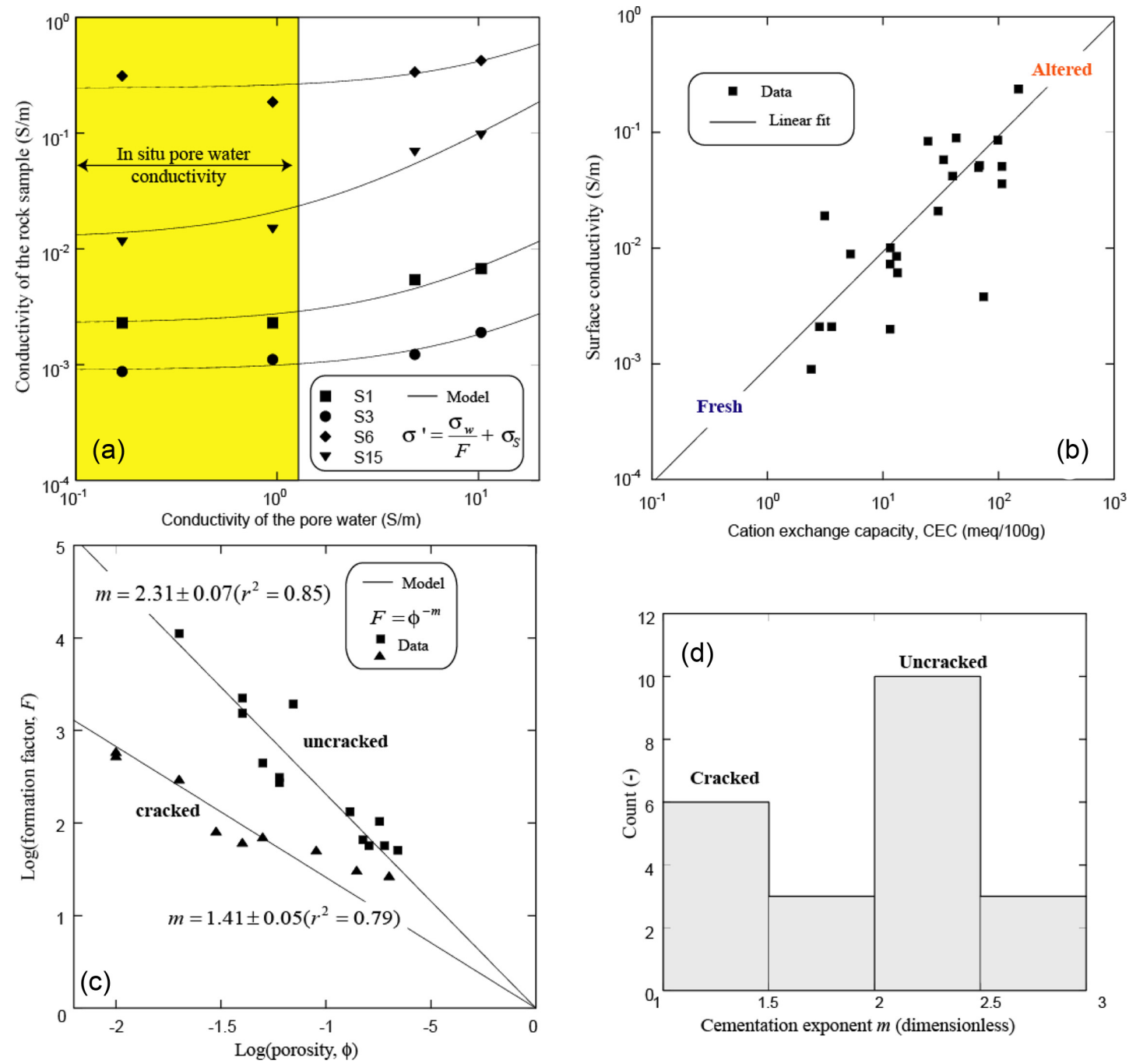

Figure 5. In-phase conductivity. (a) Conductivity of the rock sample versus pore water conductivity for 4 selected core samples. The trends are used to determine the formation factor $F$ and the surface conductivity $\sigma_{S}$. The yellow filled band corresponds to the range of in situ pore water conductivity at Kilauea (above the sea level). For this range, it is clear that the conductivity response is always dominated by the surface conductivity. (b) Surface conductivity versus cation exchange capacity (CEC). (c) Formation factor versus porosity and fits with Archie's law. (d) Distribution of the cementation exponents.

If we further assume that the surface conductivity dominates the overall conductivity response of the rock, the previous equation can be simplified to,

$M_{n}=\left(\frac{1}{F \phi}\right) \rho_{g} \lambda \mathrm{CEC}\left[1+\frac{9}{2}\left(\frac{2}{3}+\frac{B}{\lambda}\right) \varphi_{m}\right]$.

Since $B$ and $\lambda$ have the same temperature dependence, their ratio is constant and using $B\left(\mathrm{Na}^{+}, 25^{\circ} \mathrm{C}\right)=3.1 \pm 0.3 \times 10^{-9} \mathrm{~m}^{-2} \mathrm{~s}^{-1} \mathrm{~V}^{-1}$ and $\lambda\left(\mathrm{Na}^{+}, 25^{\circ} \mathrm{C}\right)=3.0 \pm 0.7 \times 10^{-10} \mathrm{~m}^{-2} \mathrm{~s}^{-1} \mathrm{~V}^{-1}$, we have $B / \lambda \approx$ 10 , so we have

$M_{n} \approx M_{n}^{2}\left[1+48 \varphi_{m}\right]$,

where we recall that $M_{n}^{2}$ refers to the normalized chargeability of the background (index 2). We can now use eq. (12) again to have an approximate equation for the quadrature conductivity,

$\sigma^{\prime \prime} \approx \frac{M_{n}^{2}}{\alpha}\left[1+48 \varphi_{m}\right]$,

$\sigma^{\prime \prime} \approx \sigma_{2}^{\prime \prime}\left[1+48 \varphi_{m}\right]$
We see therefore that a small amount of magnetite (for instance 4 vol. per cent) would amplify the overall quadrature conductivity (or the normalized chargeability) by a factor 3 ( 8 vol. per cent would amplify the quadrature conductivity or normalized chargeability response by a factor 5). We will keep this order of magnitude in mind when looking at the experimental data and to explain what we will call later the 'geoelectrical alteration path'.

\section{EXPERIMENTAL WORK}

\subsection{Core samples and experiments}

We use 24 core samples from Hole SOH-2 located on the Kilauea East Rift Zone in the Kapoho area (Fig. 1). The Scientific Observation Hole $(\mathrm{SOH})$ program was a core drilling project initiated by the State of Hawai' $i$ and performed to evaluate the geothermal potential along the east rift zone (ERZ) of Kilauea volcano (Evans 1992). The cored geological sequence is dominated by subaerial and submarine basaltic lava flows. The hole is located at an elevation of $85.4 \mathrm{~m}$ (Fig. 1). The shallow formations (down to $130 \mathrm{~m}$ ) correspond 
Table 2. Electrical properties at $0.17 \mathrm{~S} \mathrm{~m}^{-1}\left(\mathrm{NaCl}, 25^{\circ} \mathrm{C}\right)$ with the exception of $\mathrm{S} 15$ (taken at $0.95 \mathrm{~S} \mathrm{~m}^{-1}\left(\mathrm{NaCl}, 25^{\circ} \mathrm{C}\right)$. The 'partial' normalized chargeability is determined as $M_{n}(1 \mathrm{~Hz}-1 \mathrm{kHz})=\sigma^{\prime}(1 \mathrm{kHz})-\sigma^{\prime}(1 \mathrm{~Hz})$. The parameter $F$ denotes the formation factor and $\sigma_{S}$ the surface conductivity $\left(\mathrm{S} \mathrm{m}^{-1}\right)$ of the core samples.

\begin{tabular}{|c|c|c|c|c|c|c|}
\hline Sample ID & $\begin{array}{c}\sigma^{\prime}\left(\mathrm{S} \mathrm{m}^{-1}\right) \\
(1 \mathrm{~Hz})\end{array}$ & $\begin{array}{c}\sigma^{\prime}\left(\mathrm{S} \mathrm{m}^{-1}\right) \\
\quad(1 \mathrm{kHz})\end{array}$ & $\begin{array}{c}M_{n}\left(\mathrm{~S} \mathrm{~m}^{-1}\right) \\
(1 \mathrm{~Hz}-1 \mathrm{kHz})\end{array}$ & $\begin{array}{c}\sigma^{\prime \prime}\left(\mathrm{S} \mathrm{m}^{-1}\right) \\
(32 \mathrm{~Hz})\end{array}$ & $F(-)$ & $\sigma_{S}\left(10^{-3} \mathrm{~S} \mathrm{~m}^{-1}\right)$ \\
\hline S1 & $2.30 \mathrm{E}-03$ & $2.64 \mathrm{E}-03$ & $3.4 \mathrm{e}-04$ & $6.16 \mathrm{E}-05$ & $1934 \pm 396$ & $2.1 \pm 0.3$ \\
\hline $\mathrm{S} 2$ & $2.33 \mathrm{E}-03$ & $2.38 \mathrm{E}-03$ & $5.0 \mathrm{e}-05$ & $2.42 \mathrm{E}-05$ & $2242 \pm 251$ & $2.1 \pm 0.1$ \\
\hline S3 & $8.68 \mathrm{E}-04$ & $9.36 \mathrm{E}-04$ & $6.8 \mathrm{e}-05$ & $1.37 \mathrm{E}-05$ & $11200 \pm 2500$ & $0.9 \pm 0.1$ \\
\hline S4 & $1.82 \mathrm{E}-03$ & $2.11 \mathrm{E}-03$ & $2.9 \mathrm{e}-04$ & $1.78 \mathrm{E}-05$ & $1540 \pm 70$ & $2.0 \pm 0.4$ \\
\hline S5 & $6.59 \mathrm{E}-02$ & $7.18 \mathrm{E}-02$ & $5.9 \mathrm{e}-03$ & $1.09 \mathrm{E}-03$ & $27 \pm 3$ & $58 \pm 7$ \\
\hline S6 & $3.12 \mathrm{E}-01$ & $3.30 \mathrm{E}-01$ & $1.8 \mathrm{e}-02$ & $4.73 \mathrm{E}-03$ & $57 \pm 41$ & $238 \pm 53$ \\
\hline S7 & $5.28 \mathrm{E}-02$ & $5.74 \mathrm{E}-02$ & $4.6 e-03$ & $6.94 \mathrm{E}-04$ & $51 \pm 12$ & $42 \pm 9$ \\
\hline S8a & $7.19 \mathrm{E}-02$ & 7.74E-02 & $5.5 \mathrm{e}-03$ & $9.03 \mathrm{E}-04$ & $57 \pm 22$ & $51 \pm 16$ \\
\hline $\mathrm{S} 8 \mathrm{~b}$ & $4.34 \mathrm{E}-02$ & $4.59 \mathrm{E}-02$ & $2.5 \mathrm{e}-03$ & $4.64 \mathrm{E}-04$ & $66 \pm 12$ & $36 \pm 6$ \\
\hline S9 & $2.67 \mathrm{E}-02$ & $3.22 \mathrm{E}-02$ & $5.5 \mathrm{e}-03$ & $1.01 \mathrm{E}-03$ & $593 \pm 293$ & $21 \pm 4$ \\
\hline S10 & - & - & - & - & - & - \\
\hline S11 & $4.08 \mathrm{E}-02$ & $4.71 \mathrm{E}-02$ & $6.3 e-03$ & $4.22 \mathrm{E}-04$ & $82 \pm 47$ & $50 \pm 16$ \\
\hline $\mathrm{S} 12$ & $1.25 \mathrm{E}-01$ & $1.22 \mathrm{E}-01$ & - & $1.02 \mathrm{E}-03$ & $31 \pm 17$ & $86 \pm 45$ \\
\hline $\mathrm{S} 13$ & $3.98 \mathrm{E}-02$ & 4.64E-02 & $6.6 \mathrm{e}-03$ & $2.91 \mathrm{E}-03$ & $446 \pm 16$ & $3.8 \pm 0.2$ \\
\hline S14 & $7.99 \mathrm{E}-03$ & $9.59 \mathrm{E}-03$ & $1.6 \mathrm{e}-03$ & $2.66 \mathrm{E}-04$ & $535 \pm 67$ & $7.3 \pm 0.6$ \\
\hline $\mathrm{S} 15$ & $1.48 \mathrm{E}-02$ & $1.60 \mathrm{E}-02$ & $1.2 \mathrm{e}-03$ & $1.53 \mathrm{E}-04$ & $104 \pm 20$ & $8.9 \pm 2.3$ \\
\hline S16 & $2.81 \mathrm{E}-02$ & $2.88 \mathrm{E}-02$ & 7.0e- 04 & $1.04 \mathrm{E}-04$ & $133 \pm 54$ & $19 \pm 7$ \\
\hline S17 & $1.02 \mathrm{E}-02$ & $1.09 \mathrm{E}-02$ & 7.0e-04 & $1.92 \mathrm{E}-04$ & $311 \pm 88$ & $10.1 \pm 2.6$ \\
\hline S18 & $1.07 \mathrm{E}-02$ & $1.30 \mathrm{E}-02$ & $2.3 \mathrm{e}-03$ & $3.97 \mathrm{E}-04$ & $273 \pm 59$ & $8.5 \pm 1.6$ \\
\hline S19 & $6.43 \mathrm{E}-03$ & $9.76 \mathrm{E}-03$ & $3.3 \mathrm{e}-03$ & $6.64 \mathrm{E}-04$ & $298 \pm 41$ & $6.1 \pm 1.9$ \\
\hline S20 & $6.72 \mathrm{E}-02$ & $8.00 \mathrm{E}-02$ & $1.3 \mathrm{e}-02$ & $1.92 \mathrm{E}-03$ & $71 \pm 34$ & $52 \pm 15$ \\
\hline $\mathrm{S} 21$ & $1.05 \mathrm{E}-01$ & $1.05 \mathrm{E}-01$ & - & $1.16 \mathrm{E}-04$ & $62 \pm 22$ & $90 \pm 17$ \\
\hline S 22 & - & - & - & - & - & - \\
\hline S23 & $9.38 \mathrm{E}-02$ & $1.72 \mathrm{E}-01$ & $7.8 \mathrm{e}-02$ & $2.28 \mathrm{E}-02$ & $51 \pm 10$ & $84 \pm 10$ \\
\hline
\end{tabular}

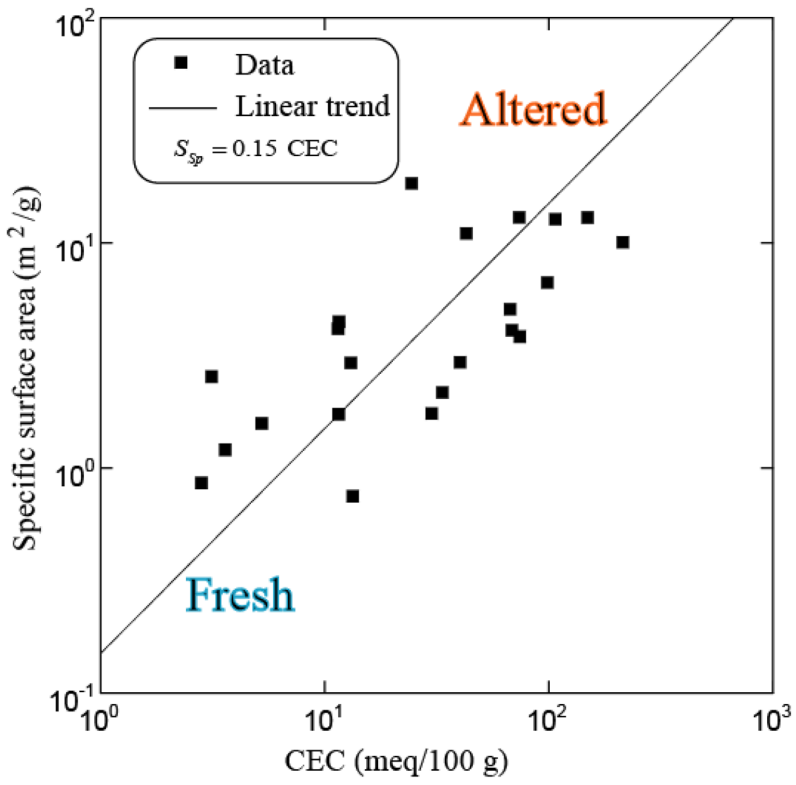

Figure 6. Relationship between the specific surface area (from BET measurements on dry samples and the cation exchange capacity (from the cobalt hexamine method).

to unaltered basalts while deeper formations are progressively altered with depth. From 1267 to 1333 m, a thick hyaloclastite deposit strongly altered to smectite was observed potentially acting as a clay cap. Hole SOH-2 therefore provides a unique set of core samples to evaluate the effect of geothermal alteration on formation electrical properties. A short description of the core sample is provided in Table 1. More information regarding the visual description of the core samples can be found in Novack \& Evans (1991).

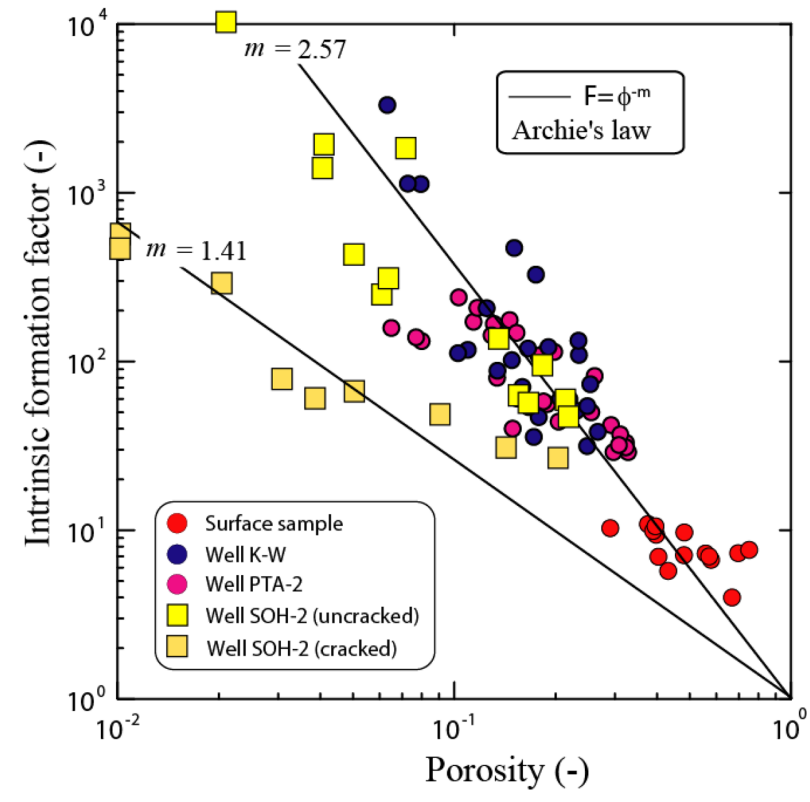

Figure 7. The intrinsic formation factor (i.e. corrected for surface conductivity) $F$ versus the connected porosity $\phi$ for the volcanic rocks from Hawai' $i$. There are 93 samples in total.

The porosity of the core samples is determined from the dry and water-saturated weights of the core samples. Saturation was obtained under vacuum. The samples were first dried at $80{ }^{\circ} \mathrm{C}$. Then, there were placed in a vacuum chamber and vacuum was performed with a pump. A degassed solution was prepared and used to saturate the sample by immersion. The water enters the samples because of the pressure gradient (one atmosphere from the centre 


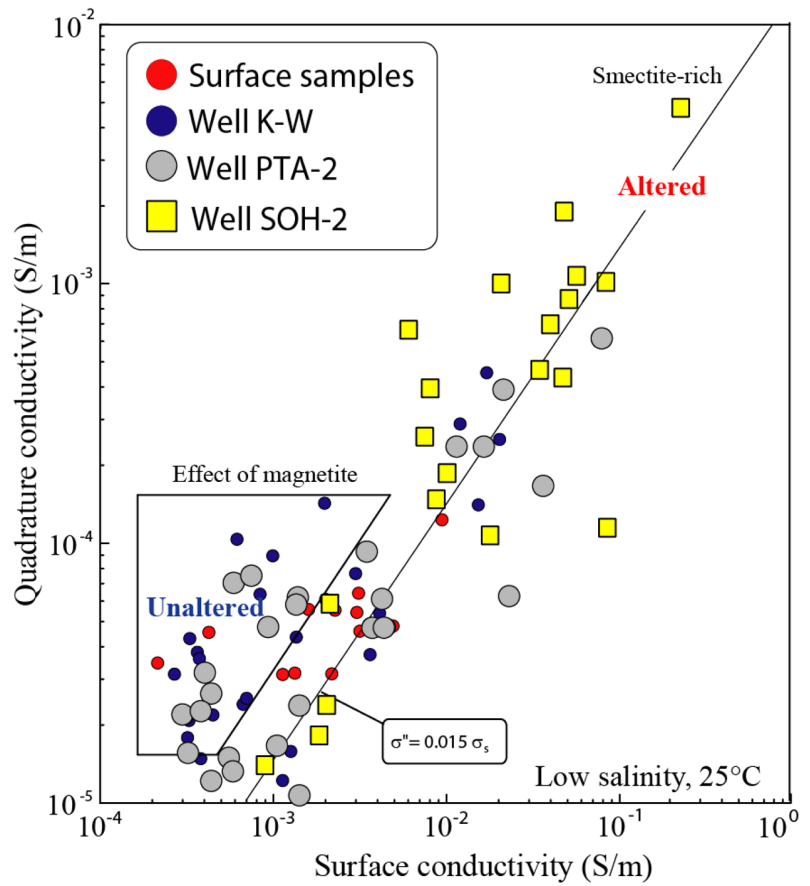

Figure 8. Magnitude of the quadrature conductivity versus surface conductivity (at a pore-water conductivity of approximately $0.1 \mathrm{Sm}^{-1}$ and taken at $1 \mathrm{~Hz}$ or $32 \mathrm{Hertz}$ ) for volcanic rocks using literature data (filled circles, $\mathrm{K}-\mathrm{W}$ stands for the Keller's well) and the present data set from Well SOH-2 (yellow-filled squares). The surface samples have been collected in 2015 at the ground surface in the caldera of Kilauea around the Halema uma 'u crater. The linear trend is independent of the value of the formation factor, saturation and temperature. Since surface conductivity is not affected by the presence of magnetite, it is a safer alteration indicator than the quadrature conductivity. Note that most of the samples located in the unaltered box of the figure have been collected at the ground surface or cored in shallow formations. There are 93 samples in total.

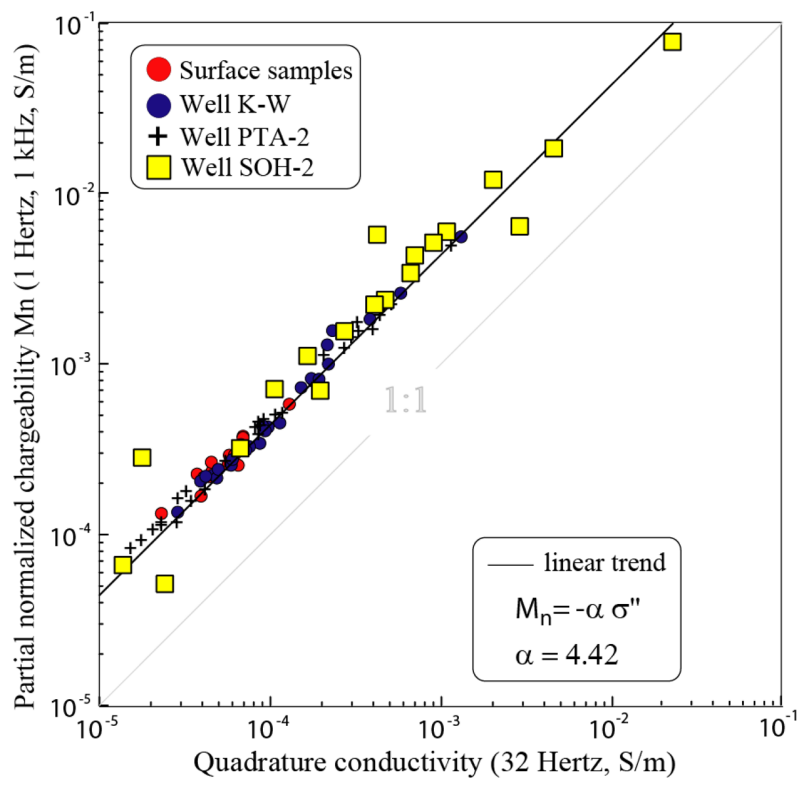

Figure 9. Normalized chargeability versus the quadrature conductivity for the volcanic samples from Hawai 'i (low salinity, $\mathrm{NaCl}, 25^{\circ} \mathrm{C}$ ). The 'partial' normalized chargeability is here determined as the difference in the in-phase conductivity between $1 \mathrm{~Hz}$ and $1 \mathrm{kHz}$ while the quadrature conductivity is determined at the geometric mean frequency of $32 \mathrm{~Hz}$. The plain line corresponds to a linear trend. The theory predicts that this trend is independent of the presence of magnetite (or pyrite) in the volcanic rocks. There are 93 samples in total.

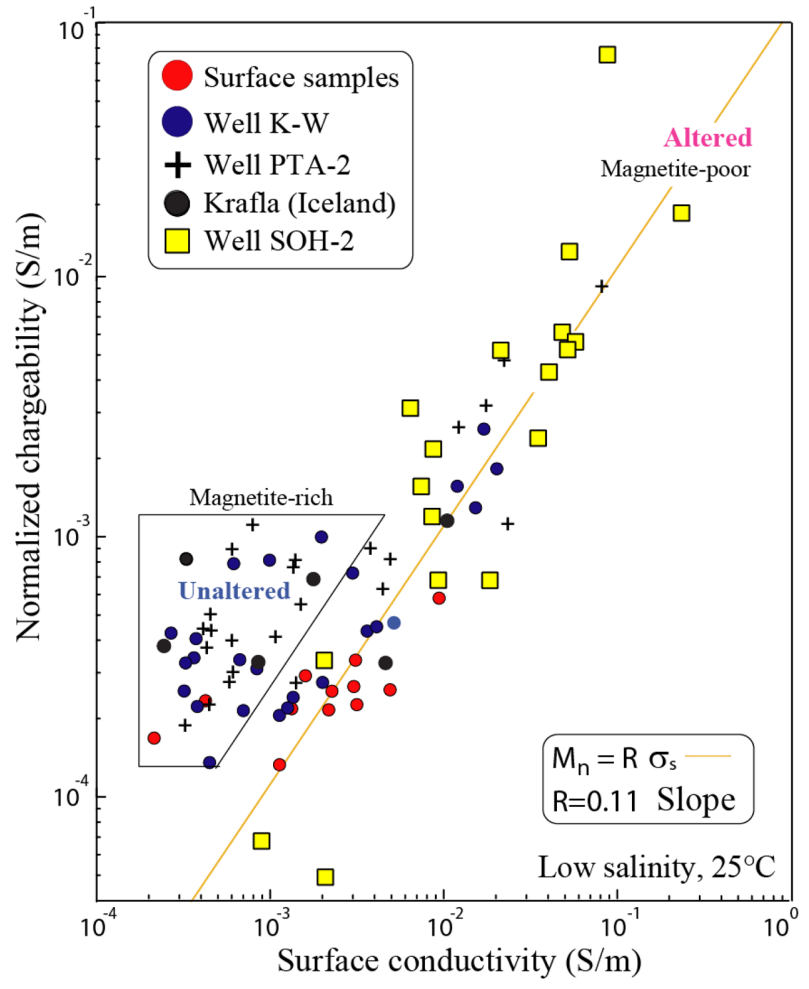

Figure 10. Linear relationship between normalized chargeability (determined between $1 \mathrm{~Hz}$ and $1 \mathrm{kHz}$ as the difference in the in-phase conductivity, low salinity, $\mathrm{NaCl}, 25^{\circ} \mathrm{C}$ ) and the surface conductivity for the volcanic samples). The measured slope leads to the following value of the dimensionless number $\mathrm{R}=0.11$. Note that most of the samples located in the unaltered box of the figure have been collected at the ground surface or cored in shallow formations.

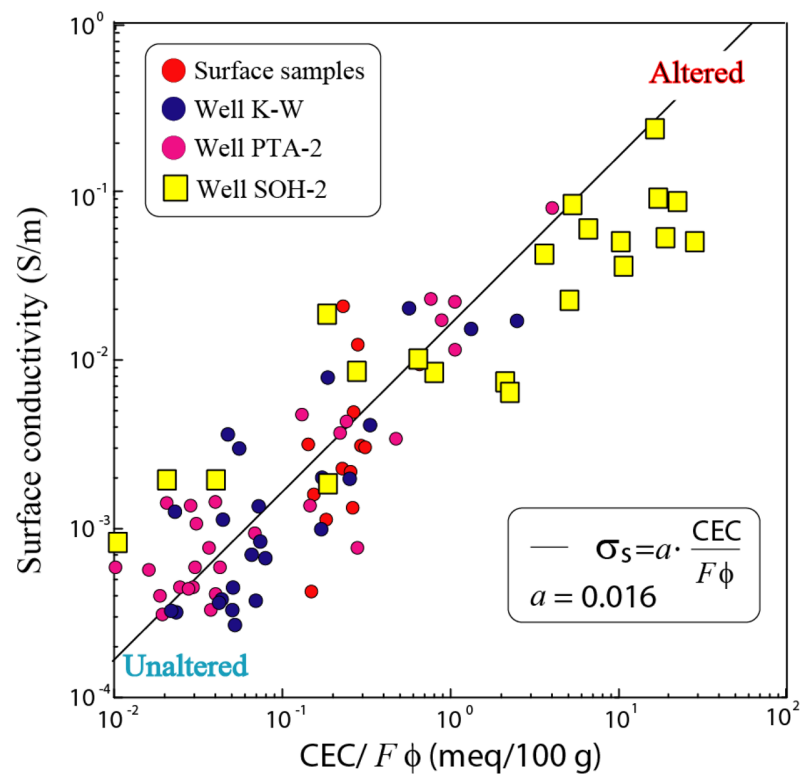

Figure 11. The surface conductivity $\left(\mathrm{S} \mathrm{m}^{-1}\right)$ versus the reduced CEC defined as $\mathrm{CEC} / F \phi$ where CEC denotes the cation exchange capacity (expressed here in meq/100 g), $F$ the formation factor and $\phi$ the connected porosity $\left(1 \mathrm{meq} /(100 \mathrm{~g})=963.2 \mathrm{C} \mathrm{kg}^{-1}\right)$. There are 93 samples in total. This trend is independent of the present of metallic conductors in the mixture. According to our model, the slope is equal to $B \rho_{g}$. Keeping in mind that the CEC is here expressed in meq $/ 100 \mathrm{~g}$, using $B\left(\mathrm{Na}^{+}, 25^{\circ} \mathrm{C}\right)=$ $3.1 \times 10^{-9} \mathrm{~m}^{-2} \mathrm{~s}^{-1} \mathrm{~V}^{-1}$ and $\rho_{g}=2900 \mathrm{~kg} \mathrm{~m}^{-3}$, we have $a=0.009$ close to the observed trend $a=0.016 \pm 0.08$. 

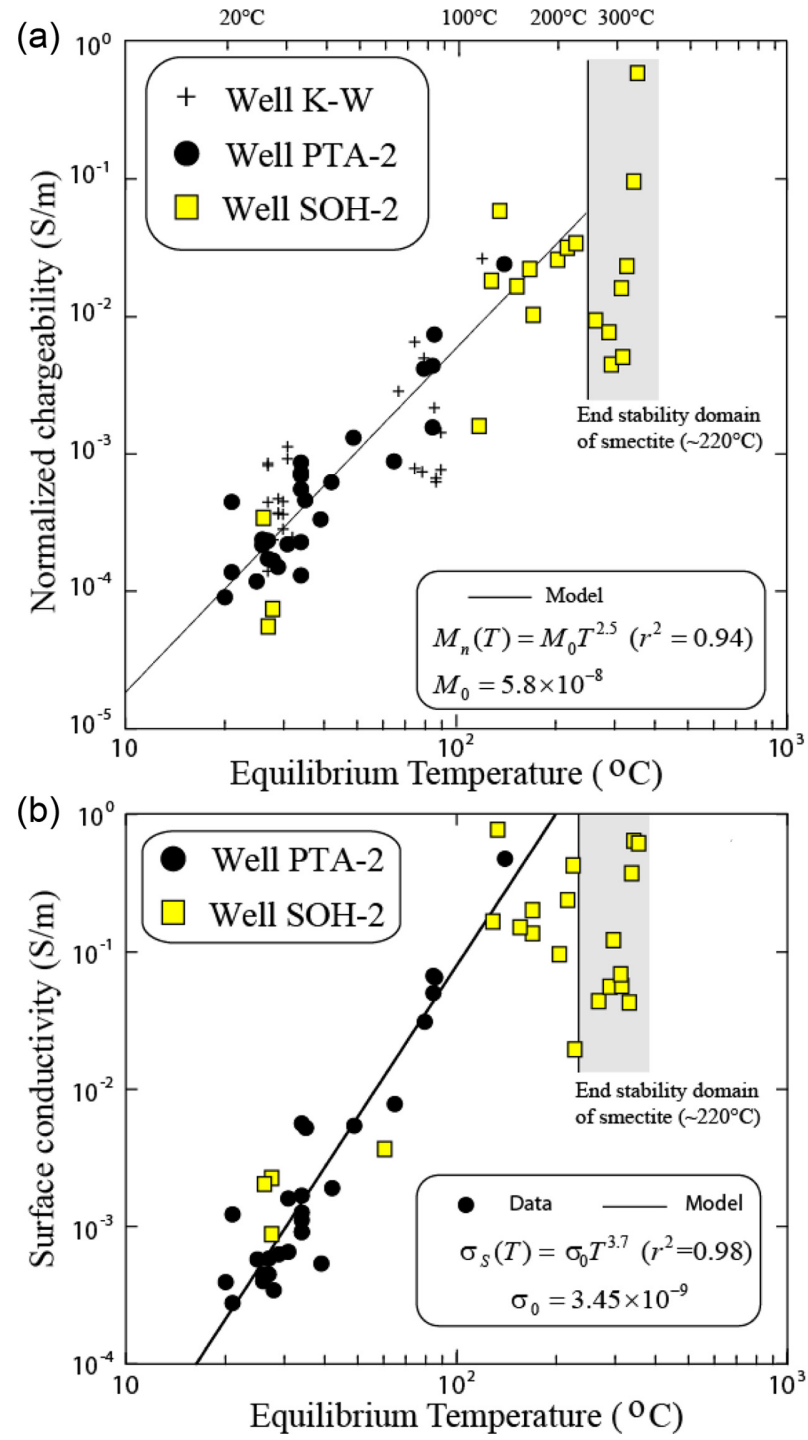

Figure 12. Normalized chargeability and surface conductivity versus equilibrium temperature in the wells. (a) Relationship between the normalized chargeability (corrected for the in situ temperature) and the equilibrium temperature (with $T$ in ${ }^{\circ} \mathrm{C}$ ) recorded in the wells. (b) Relationship between the surface conductivity (corrected for the in situ temperature) and the equilibrium temperature (with $T$ in ${ }^{\circ} \mathrm{C}$ ) recorded in the boreholes.

of the core sample to the water front). Since the invading pore water was degassed, any residual air trapped in the microporosity would be sucked into the pore water. After two weeks, the core samples are fully water saturated. Their volume is measured by immersing the saturated core samples into a bucket partially filled with water. The change of level provides a precise estimate of the volume. From the volume and the dry and saturated weights of the core sample, we can easily estimate the porosity.

The CEC measurements were performed with the cobalt hexamine method using 5-15 g of crushed rocks (see procedure in Aran et al. 2008). We use a calibrated spectrophotometer at $472 \mathrm{~nm}$. The porosity and CEC values are provided in Tables 1 (1 meq $/ 100 \mathrm{~g}=963.20 \mathrm{C} \mathrm{kg}^{-1}$ in SI units). The $\mathrm{pH}$ of the solutions is not buffered and is also reported in Table 1. The specific surface area (in $\mathrm{m}^{2} \mathrm{~g}^{-1}$ ) of the core samples was determined using the BET nitrogen adsorption technique (Brunauer et al. 1938, see Table 1). The method is used to determine the specific surface area of the

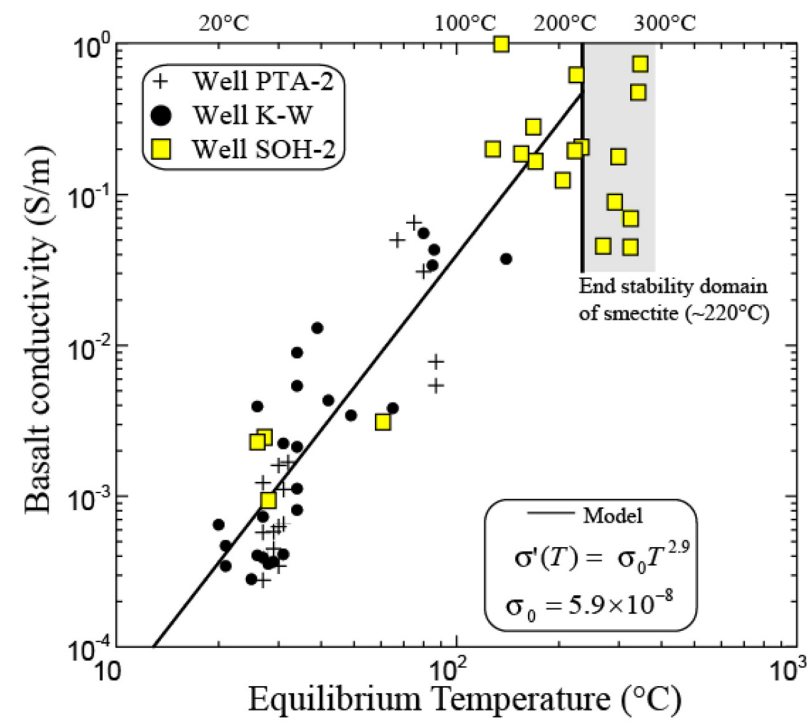

Figure 13. Electrical conductivity versus equilibrium temperature in the wells. The conductivity is corrected for the in situ temperature of the core samples in order to be used to interpret the field data. The equilibrium temperature (with $T$ in ${ }^{\circ} \mathrm{C}$ ) is recorded in the wells.

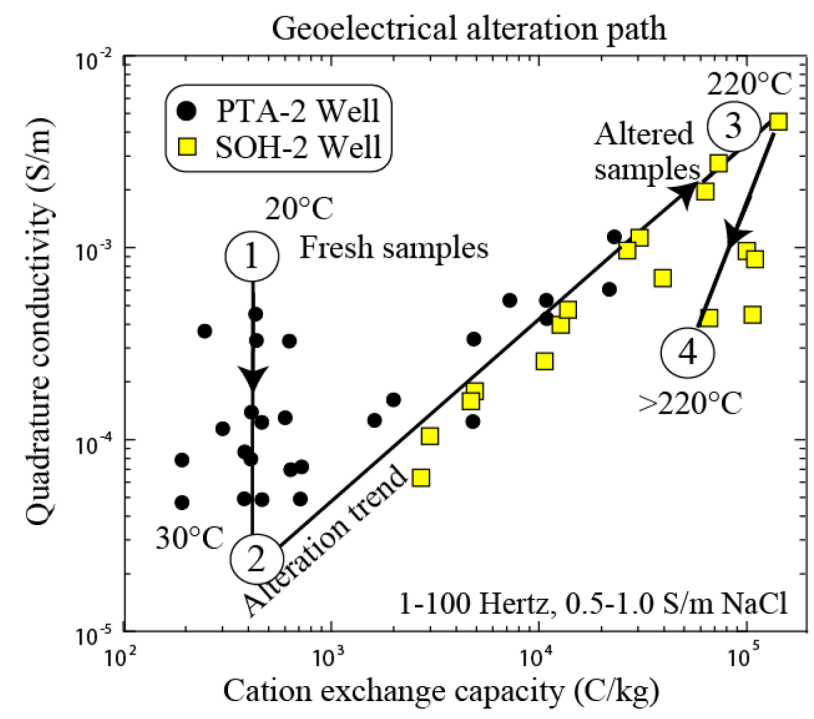

Figure 14. Geoelectrical alteration trend for the core samples from (1) fresh magnetic-rich samples to (3) smectite-rich strongly altered core samples. From (1) to (2) we observe the decrease of the magnetic content with the depth of burial. In (2) the magnetic has disappeared and the alteration starts with an increase of the content in smectite until a temperature of $220{ }^{\circ} \mathrm{C}$ is reached at (3). Both porosity and CEC change along this trend. Above $220{ }^{\circ} \mathrm{C}$, smectite is progressively replaced by chlorite and mixed-layer clays with a lower CEC. Porosity is probably not affected by these changes.

rock samples, which are first degassed at $100{ }^{\circ} \mathrm{C}(\mathrm{N} 2,77 \mathrm{~K}$, partial pressure $\mathrm{P} / \mathrm{P}^{\circ}$ comprised between 0.05 and 0.3 ). Some samples were used for X-Ray Diffraction measurements.

Frequency-domain induced polarization measurements were performed on the same 18 samples over the frequency range from 10 $\mathrm{mHz}$ to $45 \mathrm{kHz}$ using the ZELSIP04-V02 impedance meter (Zimmermann et al. 2008). We use exactly the same experimental protocol and sample holder as in Revil et al. (2017c) and this information will not be reported here. Non-polarizable $\mathrm{Ag} / \mathrm{AgCl}$ medical electrodes were used for the current injection (electrodes A and B) and 


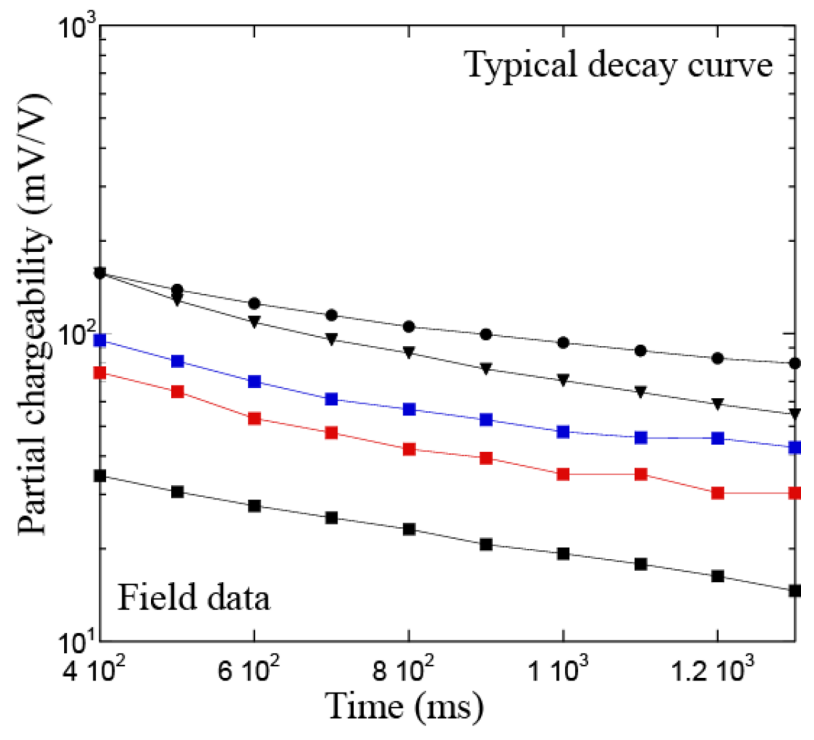

Figure 15. Selected decay curves of the partial chargeability for five selected quadrupoles ABMN (field data). A dead time of $400 \mathrm{~ms}$ is used to avoid electromagnetic coupling effects because of the total length of the cable.

potential electrodes $\mathrm{M}$ and $\mathrm{N}$. Two typical set of spectra for a low and a high CEC core sample are shown in Fig. 4 for the 4 salinities used in this work and corresponding to the following pore water conductivities $\sigma_{w}\left(\mathrm{NaCl}, 25^{\circ} \mathrm{C}\right)=0.17,0.95,4.8$, and $10.3 \mathrm{~S} \mathrm{~m}^{-1}$.

\subsection{Formation factor and surface conductivity}

Fig. 5(a) shows typical plots in which the (in-phase) conductivity of the rock samples (at $1 \mathrm{~Hz}$ ) is plotted as a function of the conductivity of the pore water $\sigma_{w}$. The data are fitted with the conductivity equation,

$\sigma^{\prime} \approx \frac{1}{F} \sigma_{w}+\sigma_{S}$

And the formation factor $\mathrm{F}$ and surface conductivity $\sigma_{S}$ are reported in Table 2. In Fig. 5(b), the surface conductivity is plotted as a function of the CEC checking the linear relationship between the two parameters. In Fig. 5(c), the formation factor is plotted as the function of the porosity for the entire data set of core samples. Samples showing cracks exhibit a much smaller cementation exponent $m=1.41$ than intact samples ( $m=2.4$, see also Fig. $5 \mathrm{~d}$ ). Fig. 6 shows a linear relationship between the specific surface area measurements and the CEC, both can be used as indicators of the degree of alteration.

In Fig. 7, we compare our data set to other data sets for basalts from Hawai' $i$ in terms of the relationship between the (intrinsic) formation factors and the connected porosity, a relationship known as Archie's law (Archie 1942). When the samples do not exhibit cracks, their cementation exponent $m$ in Archie's law is in the range 2.3-2.6. That said, as mentioned above, the presence of cracks can reduce this value to 1.4 .

\subsection{Alteration, temperature and complex conductivity}

The surface conductivity is not dependent on the presence of magnetite. In Fig. 8, we plot the absolute value of the quadrature conductivity versus the surface conductivity. According to eqs (6),
(11) and (12), the ratio between these two quantities is equal to $R / \alpha$ where $\alpha$ is defined in eq. (14). Taking $R=0.10$ and $\alpha$ $=8.8$, we obtain a ratio of 0.011 close to the observed linear trend of 0.015 . For the fresh (unaltered, shallow) core samples, we see clearly the effect of the presence of magnetite with an amplification of the quadrature conductivity response by a factor $\sim 5$ (consistent with eq. 26 for a vol per cent of magnetite of 8 per cent).

In Fig. 9, we plot the partial normalized chargeability (determined from three decades in the dispersion of the conductivity curve from $1 \mathrm{~Hz}$ to $1 \mathrm{kHz}$ ) as a function of the quadrature conductivity. As predicted by eq. (10), the slope should be equal to $\alpha \approx 4.4$ in perfect agreement with the observed slope of Fig. 9. From Figs 8 and 9, we expect therefore that the normalized chargeability versus the temperature should expect the same trend as for the quadrature conductivity versus the surface conductivity. This is indeed the case (Fig. 10).

In Fig. 11, we plot the surface conductivity as a function of the reduced CEC defined as the CEC divided by the tortuosity $F \phi$ (i.e. the product of the formation factor by the connected porosity). Our new data set is in agreement with the data from Vinegar \& Waxman (1984) and confirms the linear relationship between the two parameters. Our data set expand the trend to high values of the CEC characterize highly altered core samples.

In Figs 12 and 13, we represent the normalized chargeability, the surface conductivity and the conductivity (corrected at the in situ temperatures) as a function of the temperature in the well at the (equilibrium) temperature at which the core has been extracted. The temperature correction is done with the linear law (Revil et al. 1998) $\Theta(T)=\Theta\left(T_{0}\right)\left[1+\alpha_{T}\left(T-T_{0}\right)\right]$ where $\Theta(T)$ is any of the three properties mentioned above, $\Theta\left(T_{0}\right)$ is the same property at the reference temperature $T_{0}=25{ }^{\circ} \mathrm{C}$ (close to the laboratory temperature), and $\alpha_{T}=0.02 /{ }^{\circ} \mathrm{C}$. This correction is due to the temperature dependence of the mobilities $B$ and $\lambda$ and pore water conductivity $\sigma_{w}$ with temperature. It is however pretty small compared to the trends exhibited in Figs 12 and 13 for which a variation of 200 ${ }^{\circ} \mathrm{C}$ in temperature is responsible for a change in three orders of magnitude in the electrical conductivity and normalized chargeability. These temperature trends are therefore not directly controlled by the temperature dependence of the properties entering their petrophysical relationships. They are related to the dependence of some of these properties with the degree of alteration, especially with the presence of smectite as an alteration product (Kristmannsdóttir 1979).

Kristmannsdóttir (1979) investigated 6 high-temperature hydrothermal systems in Iceland down to $2 \mathrm{~km}$ depth. In this study, hydrothermal alteration took place in basaltic hyaloclastites and lavas in the temperature range $100-300{ }^{\circ} \mathrm{C}$. She observed that the same alteration minerals were formed at the same equilibrium (formation) temperature with smectites (especially iron-rich saponites) and zeolites formed at temperatures below $200{ }^{\circ} \mathrm{C}$. In the temperature range $200-230{ }^{\circ} \mathrm{C}$, these smectites were transformed into mixedlayer clay minerals and chlorites. Chlorite becomes the dominant mineral above $240{ }^{\circ} \mathrm{C}$ (see also Árnason et al. 2010). In this study, clay minerals appeared to be the most significant alteration minerals. Since the CEC of smectite is substantially higher than the CEC of chlorite (and other clay minerals), the change observed in Figs 12, 13 , and 14 on the electrical properties can be therefore easily explained. Figure 14 shows the geoelectrical alteration path followed by core samples during their burial and concomitant temperature increase. 

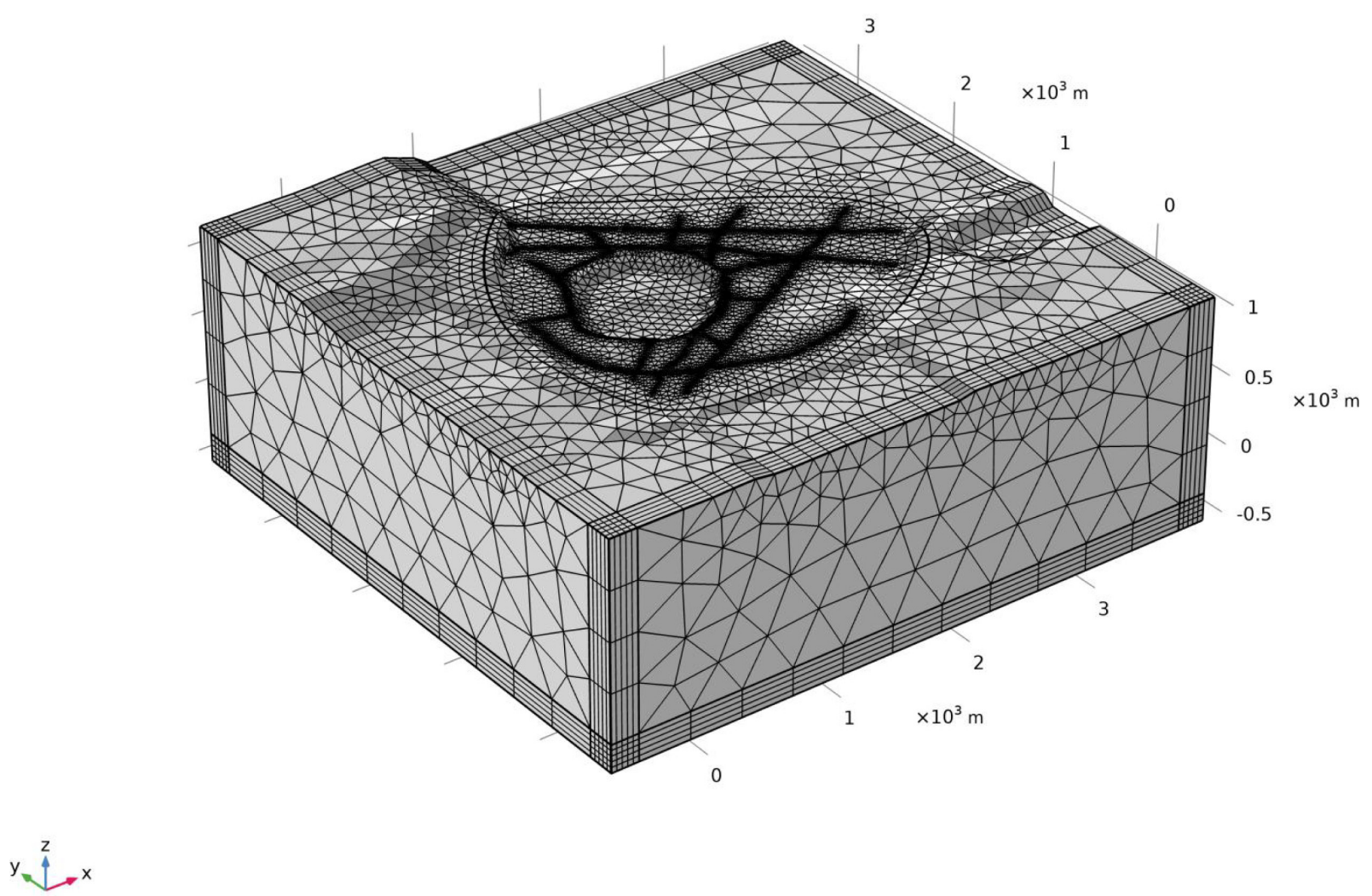

Figure 16. Mesh used for the inverse problem of the tomography including the padded area around the area of interest used to satisfy to the boundary conditions. 109619 elements are generated for the whole domain.

\section{FIELD APPLICATION}

\subsection{Data acquisition}

A total of 10 geophysical profiles were setup in the vicinity of the Halema' uma' $u$ crater in November 2015. All the profiles are measured by an ABEM Terrameter SAS-4000 with Wenner-type array with 64 stainless steel electrodes. The data were acquired along profiles around the crater to be able to have sensitivity below the crater itself. The spacing between the electrodes is $40 \mathrm{~m}$ and a total of 465 electrodes were used. The dataset includes 4210 apparent resistivity and chargeability data. Typical decay curves for the partial chargeabilities are shown in Fig. 15.

\subsection{Forward and inverse modelling}

Induced polarization is here modelled through its effect on the electrical conductivity (Seigel 1959). The fundamental field equation to solve remains the classical elliptic equation for the conductivity problem:

$\nabla \cdot(\sigma \nabla \psi)=-I \delta\left(\mathbf{r}-\mathbf{r}_{\mathrm{s}}\right)$

where $I$ (in A) denotes the injected current (negative of retrieved), $\delta\left(\mathbf{r}-\mathbf{r}_{\mathrm{s}}\right.$ ) denotes the delta function ( $\mathbf{r}$ and $\mathbf{r}_{\mathrm{s}}$ are the vector position and the position vector of the current source, respectively), $\sigma$ (in $\mathrm{S} \mathrm{m}^{-1}$ ) denotes the conductivity of the subsurface and $\psi$ the electrical potential (in Volt). A Dirichlet boundary condition $\psi=0$ is applied at the far boundaries of the investigated area (see Fig. 16). A Newman boundary condition $\partial \psi / \partial n=0$ is applied at the ground surface (insulating boundary conditions), where $n$ denotes the unit normal vector to ground surface. Regarding induced polarization, the polarization of the grains reduces the conductivity of the rock and for dc conditions, we have $\sigma_{0}=(1-M) \sigma_{\infty}$, where $\sigma_{0}$ denotes the dc conductivity. The instantaneous conductivity, $\sigma_{\infty}$, represents the high-frequency conductivity for which all the charge carriers are mobile. The chargeability is defined as $M=\left(\sigma_{\infty}-\sigma_{0}\right) / \sigma_{\infty}$.

Considering the topography of the Halema 'uma ' $u$ crater, we used the high-resolution DEM file with 10-m resolution in our geometric model (Fig. 2). Since the current density decay is inversely proportional to the square of the distance from the source electrodes, we build our model into three domains, the core, the buffer and the boundary domains, which are shown in Figs 16 and 17. The finite element method is used to solve the elliptic equation for the conductivity problem. Unstructured free tetrahedral meshes are used to discretize the geometric model (e.g. Qi et al. 2019). To precisely capture the signal characteristics, meshes are locally refined near the electrodes in the core domain (Figs 16 and 17). The far-field Dirichlet boundary condition is applied thanks to the infinite element method that greatly reduces the domain size without losing accuracy (Qi et al. 2019). A total of 109619 mesh elements are generated for the whole domain and 82884 for the core domain.

The inversion of time-domain induced polarization data is carried out in two steps. We first perform an inversion of the conductivity field and then we model the chargeability field (e.g. Oldenburg \& Li 1994; Qi et al. 2018). Since both conductivity and chargeability inversions are mathematically ill-posed, regularized least-squares method is used via minimizing the objective function

$\mathbf{P}^{\beta}(\mathbf{m})=\left\|\mathbf{W}_{d}\left(\mathbf{d}(\mathbf{m})-\mathbf{d}_{\mathrm{obs}}\right)\right\|^{2}+\beta\left\|\mathbf{W}_{m} \mathbf{m}\right\|^{2}$, 


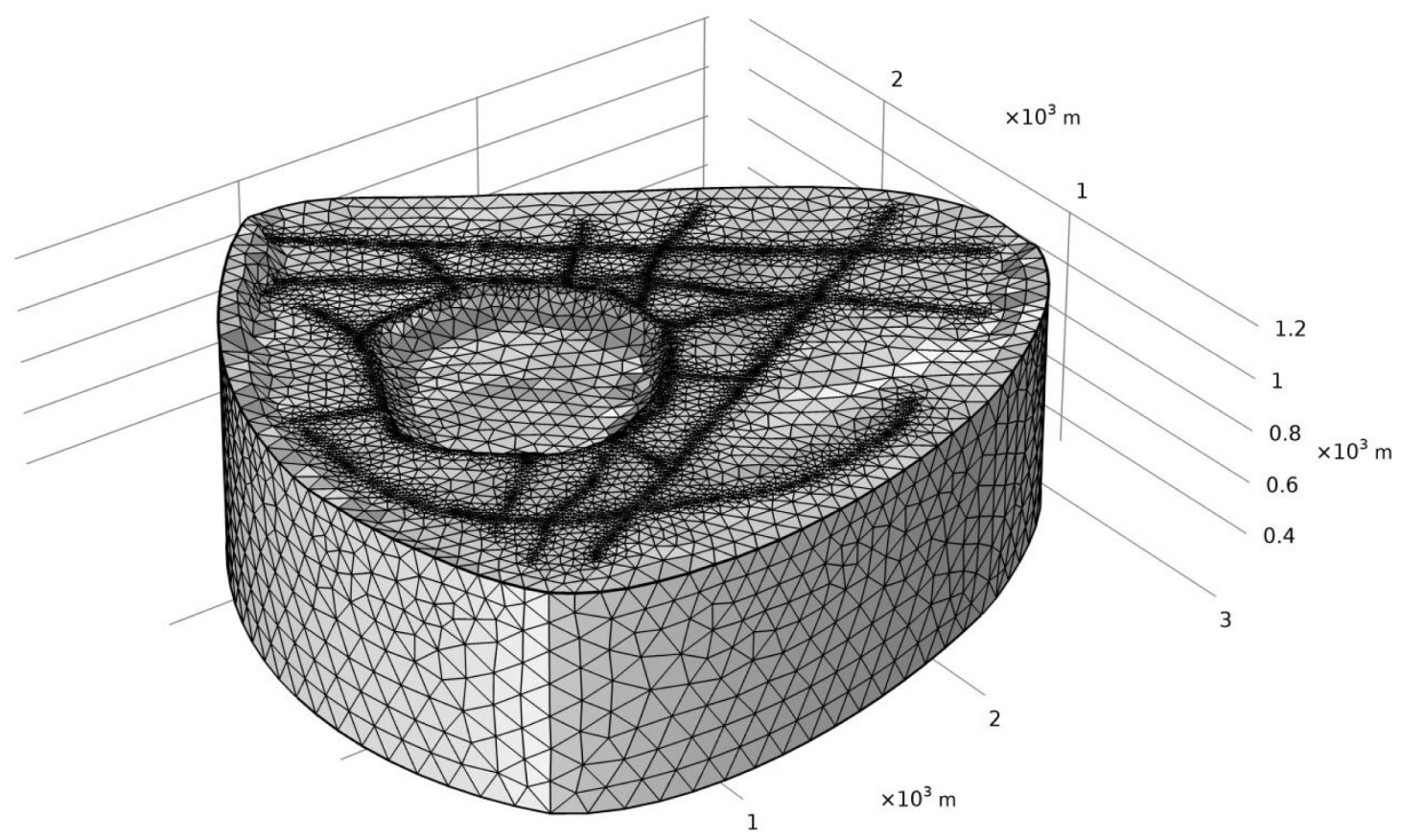

$\sqrt{2} x$

Figure 17. Mesh used for the inverse problem of the tomography corresponding to the area of interest (core domain). Note the finer mesh around the electrodes of the profiles. A total of 82884 elements have been used for the simulations in the core domain. The curvilinear profiles around the crater were used to provide sensitivity below this structure since we did not get the authorizations to enter the crater during the field work.

where $\mathbf{m}$ denotes the model vector with the logarithm of the conductivity of each cell in the core domain, $\beta$ is the regularization parameter that trades the data misfit off the smoothness, the vectors $\mathbf{d}(\mathbf{m})$ and $\mathbf{d}_{\mathrm{obs}}$ are the forward modelled data and field measured (observed) data, respectively, $\mathbf{W}_{d}$ is the data covariance matrix for the observed data and $\mathbf{W}_{\text {obs }}$ denotes the first-order gradient matrix to reduce the roughness of the model. The minimization of eq. (29) is solved via the Gauss-Newton method with the model vector perturbation as

$$
\begin{aligned}
\delta \mathbf{m}= & {\left[\mathbf{J}^{T}\left(\mathbf{W}_{d}^{T} \mathbf{W}_{d}\right) \mathbf{J}+\beta \mathbf{W}_{m}^{T} \mathbf{W}_{m}\right]^{-1} } \\
& \times\left[\mathbf{J}^{T}\left(\mathbf{W}_{d}^{T} \mathbf{W}_{d}\right)\left(\mathbf{d}_{o b s}-\mathbf{d}\left(\mathbf{m}_{k}\right)-\beta \mathbf{W}_{m}^{T} \mathbf{W}_{m} \mathbf{m}_{k}\right],\right.
\end{aligned}
$$

where $\mathbf{J}$ is the sensitivity matrix which is calculated by the adjoint method in our inversions. Once the inversion is finished, the normalized chargeabilities are computed cell by cell by the product of the conductivities and the chargeabilities. Our inversions have already been benchmarked on synthetic and field data (Qi et al. 2018) and such tests will not be repeated here.

\subsection{Results and interpretation}

The conductivity and normalized chargeability tomograms are shown in Fig. 18 at the 8th iteration (see Fig. 19 for the evolution of the RMS error as a function of the number of iteration). From the conductivity tomogram, we observe low electrical conductivity values $\left(<10^{-4} \mathrm{~S} \mathrm{~m}^{-1}\right)$ at the surface dry basalts) and far from the crater. Moderate $\left(10^{-4}\right.$ to $\left.0.1 \mathrm{~S} \mathrm{~m}^{-1}\right)$ to high conductivity values $\left(>0.1 \mathrm{~S} \mathrm{~m}^{-1}\right)$ are observed around the crater rim and at depth.
This is in agreement with the observations made by Kauahikaua \& Mattice (1981). The conductivity and normalized chargeability tomograms show almost the same pattern (see also Fig. 18). It is reasonable to infer that the surface conductivity play therefore a stronger role than the conductivity contribution associated with the pore water conductivity. This can be further proved when we plot the normalized chargeability with respect to the conductivity (Fig. 20). This ratio is close to $R=0.10$ indicating that surface conductivity dominates the overall conductivity response (Ghorbani et al. 2018; Revil et al. 2018) in the areas of the Halema 'uma' $u$ crater, which is in consistent with our laboratory measurements (Fig. 5a).

We apply now the empirical power relationships for the relationships between the normalized chargeability and the temperature (Fig. 12) and between the conductivity and the temperature (Fig. 13). From Fig. 21, the conductive features on the west edge of the crater are aligned with the trajectory of the Kilauea Southwest Rift zone (Swanson et al. 2018). The conductivity is likely associated with persistent degassing from the shallow magma reservoir through the rocks overlying the fracture network that extends from the magma chamber out to the SW Rift (Neal \& Lockwood 2003). We see the conductive features corresponding with acid leached ground along the norther edge of the crater. At the eastern edge of the crater there is also an alignment of conductive ground with the eruptive fissures of the 1954, 1975 and 1982 (short lived) summit eruptions. The conductive feature on the southern edge of the caldera is associated with the persistent (for five decades) degassing region. It is somewhat south of the trajectory toward the SW Rift Zone but this area has been degassing at least since the early 1970s and the ground 
(a) Electrical conductivity tomogram
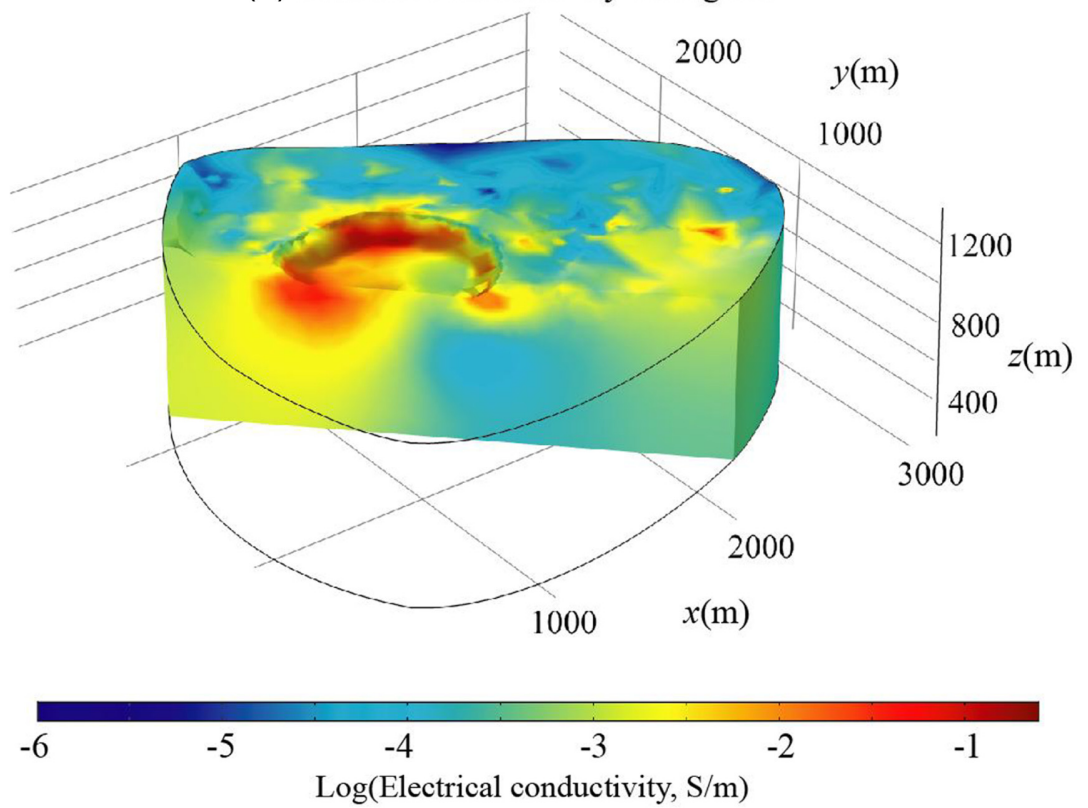

\section{$-1$}

(b) Normalized chargeability tomogram

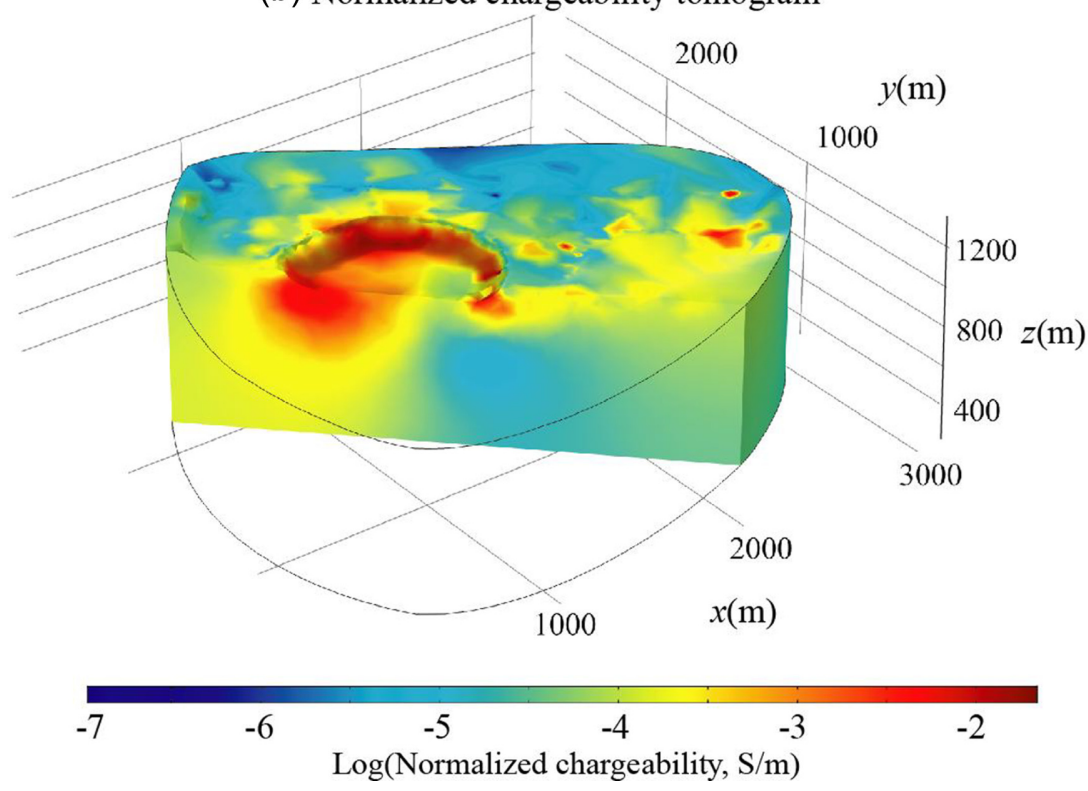

Figure 18. Tomograms based on a total of 6210 measurements in the core domain. (a) Electrical conductivity tomogram (in $\mathrm{S} \mathrm{m}^{-1}$ ). (b) Normalized chargeability tomogram (in $\mathrm{S} \mathrm{m}^{-1}$ ). Note the very similar structures obtained using the two properties, which indicates right away that the conductivity field is dominated by its surface (interfacial) conductivity contribution associated with conduction in the electrical double layer coating the surface of the grains.

surface is extensively altered by sulfuric and hydrochloric acids. On the eastern flank of the crater, the conductive feature corresponds to the 1971 and 1974 fissure fumaroles that extent out of the caldera to the 'connector' conduit to Kilauea's East Rift Zone. This has discharged high concentrations of sulfur dioxide for several decades and formed the South Sulfur Bank.

\section{DISCUSSION}

The core samples used in the present investigation comes from a drilling project performed $30 \mathrm{yr}$ ago. Therefore the used samples spent $30 \mathrm{yr}$ stored in different condition (pressure and temperature) than the in situ conditions. The data are however consistent with core samples from more recent drillings so this could mean that their composition (smectite, magnetite) should not have changed over time. The laboratory measurements are used to assess the physics of the relationships between the geoelectrical parameters (conductivity and normalized chargeability) and the in situ temperature, which has affected in turn their degree of alteration and especially the production of smectite (see Fig. 22a). Fig. 22(b) shows that magnetite disappears essentially before the percentage of clays associated with alteration takes off. Once the physics connecting induced polarizing properties and alteration has been validated, it is used to interpret the field measurements. Consequently, the fact that 


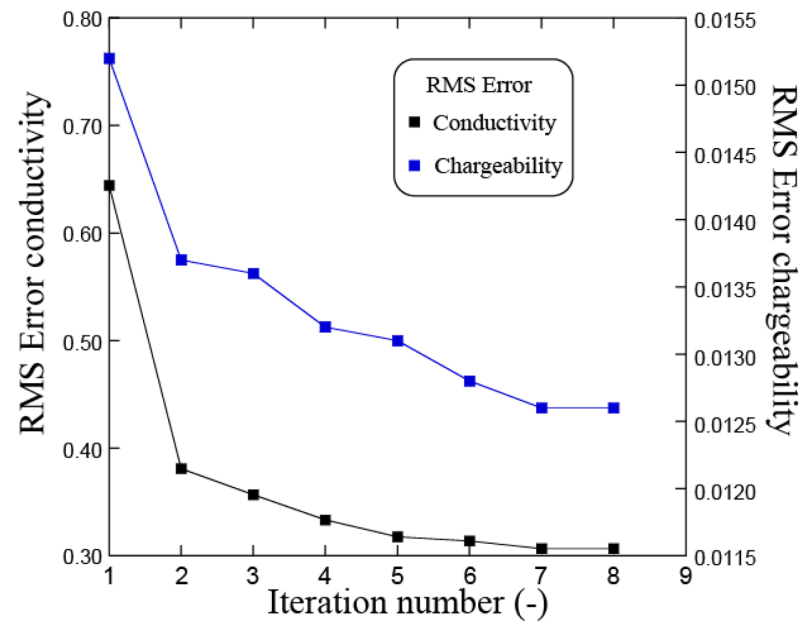

Figure 19. Evolution of the RMS error for the inversion of the apparent resistivity and chargeability data. The inversion is stopped at iteration 8 .

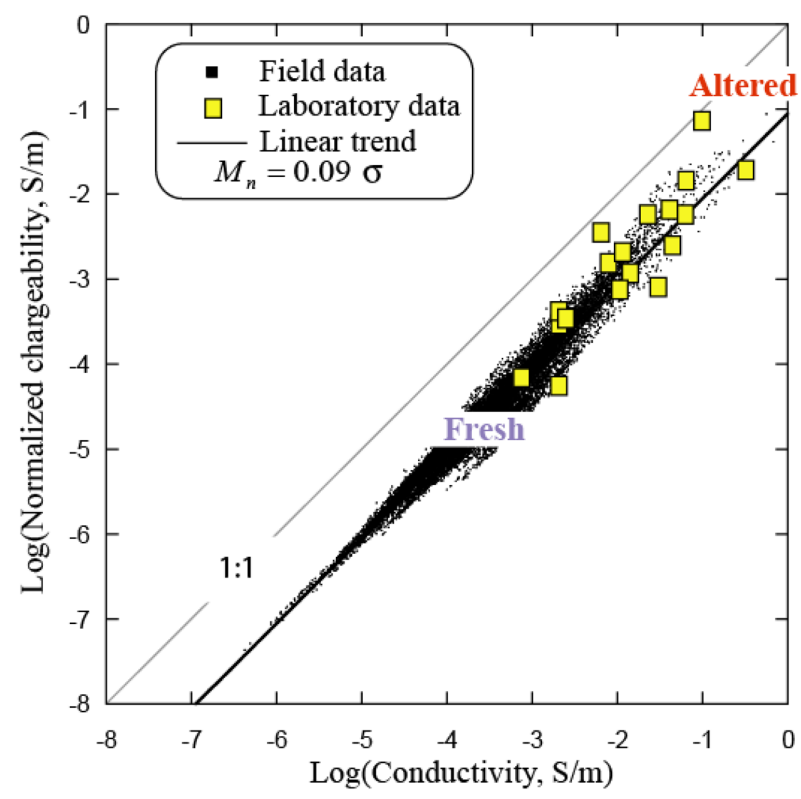

Figure 20. Normalized chargeability versus conductivity in the field and comparison with the laboratory data from this study (Well SOH-2). When the relationship between the normalized chargeability and the conductivity is given by $M_{n}=R \sigma$ with $R=0.09 \pm 0.02$, this means that the conductivity field is dominated by its surface conductivity contribution, which is proportional to the normalized chargeability.

the field measurements were taken $25 \mathrm{yr}$ after the drilling program does not impact the procedure used in our investigation to use old core samples.

The second point to discuss is the uncertainty associated with the estimate of the temperature field. We can estimate the uncertainty on the distribution of the conductivity and normalized chargeability fields by looking at the posterior covariance matrix on the model vector. In addition, we need to assess the uncertainty associated with the petrophysical transform, which can be considered as a mean trend plus a log normal uncertainty. The standard deviation of the log normal distribution can be computed from the variance in the distribution of the data points around the mean values in Figs 12 and 13. That said, there are probably better ways to invert the temperature field in volcanoes by merging the induced polarization data with a prior temperature distribution obtained using well data and solving for the temperature equation with appropriate boundary conditions and thermal property distribution. We let the development of this approach to a future paper.

In this paper, we have not discussed the effect of the conductivity of the ground water on the temperature distribution. Tilling \& Jones (1996) provides the composition of the ground water close to the caldera of Kilauea and from the Keller's well. These results are summarized in Table 3. From this table we can see that sodium is the dominant cation like in the laboratory experiments. The mean TDS is $2600 \pm 200 \mathrm{mg} \mathrm{L}^{-1}$. Using $\operatorname{TDS}\left(\mathrm{mg} \mathrm{L}^{-1}\right)=k \sigma_{\mathrm{w}}(\mu \mathrm{S}$ $\mathrm{cm}^{-1}$ ) with $k=0.7$ (Taylor et al. 2018), this leads to a ground water conductivity at $25{ }^{\circ} \mathrm{C}$ around $3700 \mu \mathrm{S} \mathrm{cm}{ }^{-1}\left(\sigma_{\mathrm{w}}=0.37 \mathrm{~S} \mathrm{~m}^{-1}\right.$ at $25^{\circ} \mathrm{C}$ ). The $\mathrm{pH}$ is $8.2 \pm 0.2$ in good agreement with the values inferred in Table 1. Therefore the conditions used to determine the relationships between the electrical properties and the temperatures in the laboratory (salinity, type of salt, $\mathrm{pH}$ ) are consistent with the in situ conditions.

From the previous considerations, we can see how an uncertainty in the conductivity estimate would translate into an uncertainty in the temperature estimate. From the power-law relationship determined for the conductivity/temperature estimate established in Fig. 13, we have,

$$
\frac{\delta T}{T} \approx \frac{1}{3} \frac{\delta \sigma}{\sigma} .
$$

Because of the error due to the inversion of the apparent conductivity data and the effect of salinity, we can assume a maximum uncertainty in 30 per cent of the conductivity values. Because of the power-law relationship, this would translate into a 10 per cent uncertainty in the temperature, which is acceptable.

The last point we wish to discuss if how to perform high quality induced polarization measurements in the field. In the present investigation, we used a long $(2.5 \mathrm{~km})$ cable. We learn that to minimize spurious results, the current electrodes should never be used for a duration of $5 \mathrm{~min}$ as voltage electrodes. We did not stack more than twice the measurements and the dead time after shutting down the primary current should be considered carefully to avoid spurious results associated with electromagnetic coupling effects. In the future, decentralized recording stations as discussed in the previous paper of this series (Gross et al. 2021) will help in getting high quality induced polarization signals in volcanic areas. This will open the door to large scale galvanometric induced polarization surveys on volcanoes.

\section{CONCLUSIONS}

The conclusions reached in this paper are the following:

(1) A new data set of experimental data has been developed using core samples from the high temperature well (SOH-2) showing high degree of alteration at depth. This alteration is proved through the CEC and specific surface area measurements. Highly altered samples are rich in smectite with high normalized chargeability and conductivity. The experimental data (including those from the literature) are explained by a mixture model combining the polarization of the non-metallic grains and the polarization of the metallic grains (pyrite and magnetite). 
(a) Temperature field $\left({ }^{\circ} \mathrm{C}\right)$
Normalized chargeability
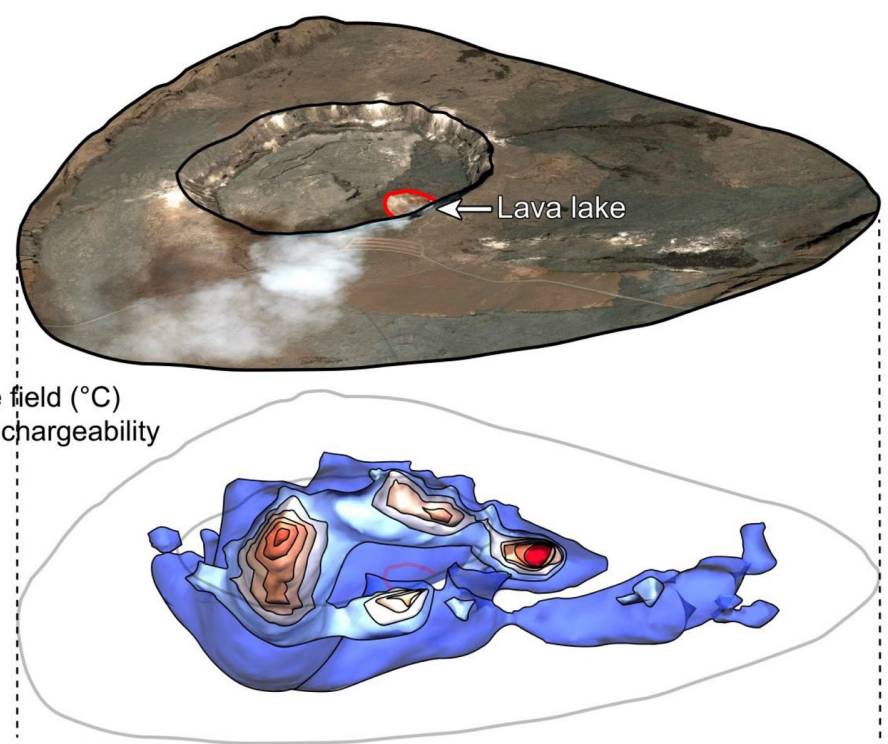

(b) Temperature field $\left({ }^{\circ} \mathrm{C}\right)$

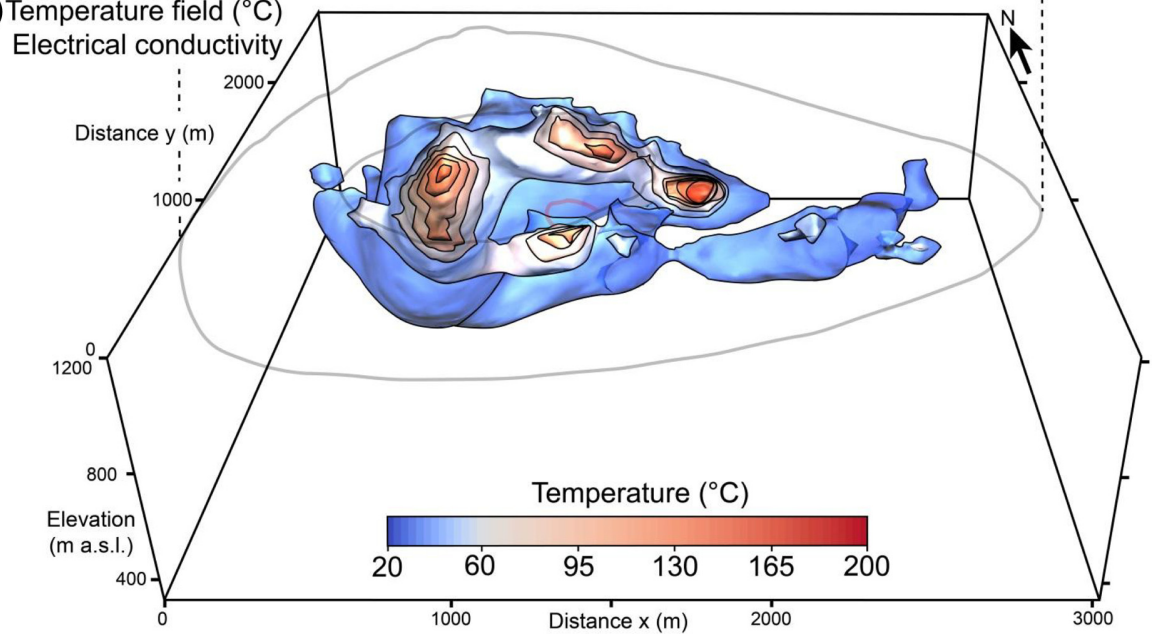

Figure 21. Temperature distribution from the conductivity and induced polarization methods. (a) Result from the conductivity distribution. (b) Result from the normalized chargeability distribution.

(2) During burial, the conductivity of the volcanic rocks is quickly dominated by the conductivity associated with conduction in the electrical double layer coating the surface of the grains. Therefore, in volcanoes the electrical conductivity of volcanic rocks is quickly controlled by their degree of alteration rather than by the conductivity of the pore water. The presence of smectite resulting from alteration is strongly temperature dependent. Therefore, the conductivity does not depend on porosity the way proposed by the classical Archie's law adopted classically as a conductivity equation (note that fundamentally Archie's law is a relationship between the formation factor and the porosity independent of the relative importance of surface conduction). The control exerted by surface conduction is further assessed by the relationship between the electrical conductivity and the normalized chargeability.

(3) The conductivity and the normalized chargeability strongly depend on the equilibrium temperature of the formation (up to 220 ${ }^{\circ} \mathrm{C}$ ) because of the impact of the equilibrium temperature on the degree of alteration (and therefore on both the CEC and the porosity). A change of the conductivity and normalized chargeability by three orders of magnitude is observed for a change of temperature of $\sim 200^{\circ} \mathrm{C}$. This is far greater than the classical dependence of the conductivity of a volcanic rock sample with temperature due to the temperature dependence of the ionic mobilities with temperature ( 2 per cent per degree Celcius, so a change of temperature of 200 ${ }^{\circ} \mathrm{C}$ implies a change in the electrical properties by a factor 4). The proposed relationships can be applied to conductivity data (from galvanometric or electromagnetic measurements) and to normalized chargeability data to map in 3-D the equilibrium temperature of volcanoes.

(4) An example of the procedure is illustrated for the Halema uma 'u pit crater of Kilauea volcano in Hawai'i. For the first time, to the best of our knowledge, a 3-D induced polarization tomography of a volcano is performed. The results are interpreted using the petrophysical model developed in this paper. The relationship observed between the normalized chargeability and the conductivity underlines the strong role played by surface conduction in the electrical double layer. Furthermore, a 3-D temperature map of the crater is proposed and the high-temperature areas are identified with respect to areas know to be degassing and altered areas. 

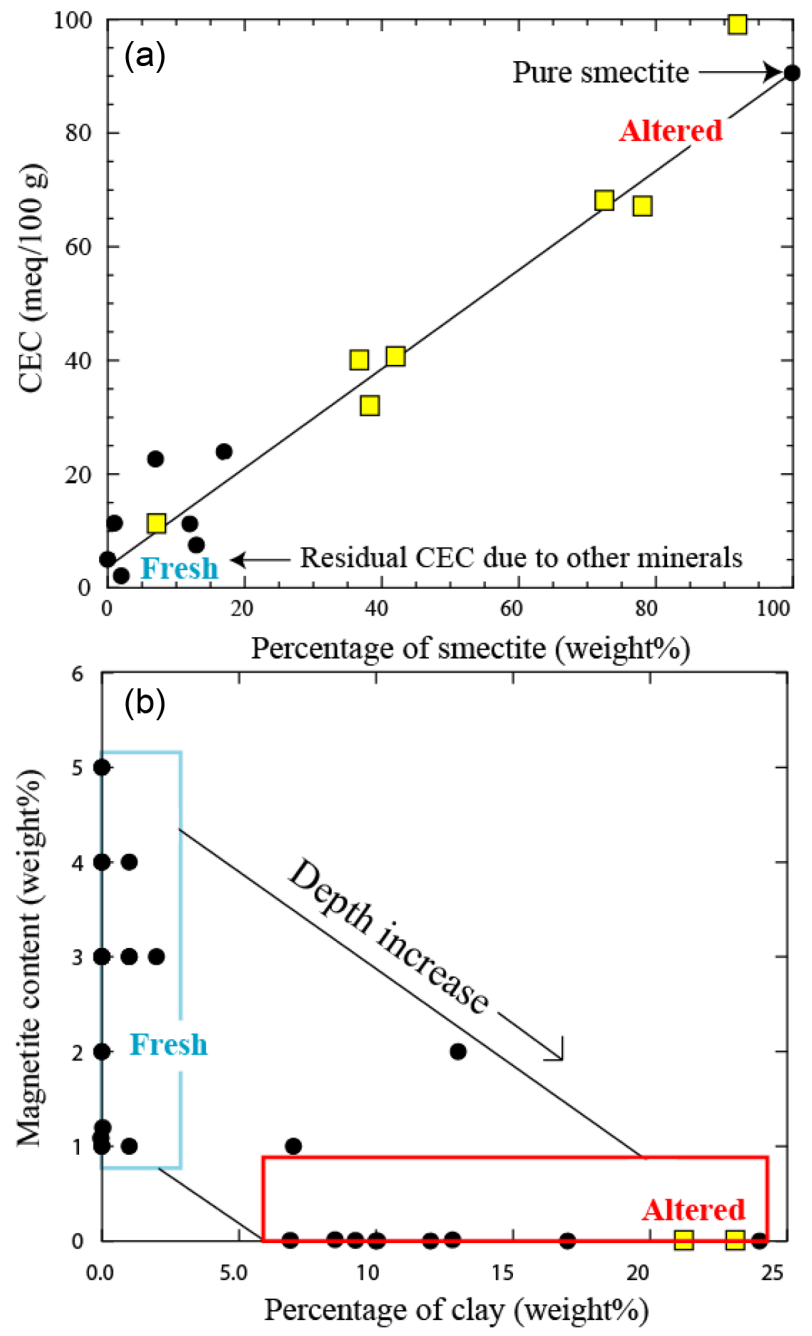

Figure 22. Smectite and magnetic for fresh and altered basalts. (a) Relationship between the CEC and the percentage of smectite (from XRD, X-Ray Diffraction measurements) for the core samples (the yellow-filled square are new data, the filled circles are from Revil et al. 2018). (b) Magnetite versus percentage of clays. The samples obtained from the present study do not contain magnetite.

Table 3. Water samples from Keller's well, a 1262-m-deep research borehole at the summit of Kilauea Volcano. The concentrations are given in $\mathrm{mg} \mathrm{L}^{-1}$. For the TDS, $1 \mathrm{ppm}$ corresponds to $1 \mathrm{mg} \mathrm{L}^{-1}$ assuming that the density of water is $1.00 \mathrm{~g} \mathrm{~mL}^{-1}$.

\begin{tabular}{lcccccc}
\hline Sample & $\mathrm{Ca}$ & $\mathrm{Mg}$ & $\mathrm{Na}$ & $\mathrm{K}$ & $\mathrm{TDS}$ & $\mathrm{pH}$ \\
\hline KBW-1 & 49 & 39 & 740 & 90 & 2780 & 8.5 \\
KBW-2 & 47 & 43 & 720 & 104 & 2830 & 8.5 \\
KBW-3 & 52 & 42 & 710 & 115 & 2850 & 8.5 \\
KBW-4 & 36 & 22 & 545 & 47 & 1900 & 8.7 \\
KBW-5 & 105 & 51 & 700 & 124 & 3070 & 8.2 \\
KBW-6 & 62 & 65 & 750 & 140 & 3260 & 8.1 \\
KBW-7 & 63 & 79 & 759 & 142 & 3360 & 8.2 \\
KBW-8 & 49 & 64 & 769 & 142 & 3230 & 8.3 \\
KBW-9 & 72 & 87 & 730 & 111 & 3050 & 7.6 \\
KBW-10 & 101 & 72 & 537 & 90 & 2390 & 8.0 \\
KBW-11 & 104 & 69 & 490 & 66 & 2180 & 8.0 \\
KBW-12 & 104 & 107 & 221 & 44 & 1390 & 8.1 \\
KBW-13 & 106 & 110 & 214 & 43 & 1380 & 8.0 \\
\hline
\end{tabular}

\section{ACKNOWLEDGEMENTS}

This study was funded by INSU,CNRS (fra). We are grateful to T. Neal, J. Sutton, S. Swanson, S. Brantley, N. Grobbe and the HVO's staff in Hawai'i for their support. We also thank the HVO Park for its support and access authorization. We thank J. Kauahikaua, L.S. Gailler, N. Cluzel and J.F. Lénat for their help in the field. We thank A. Coperey (GEOREVA) for performing part of the laboratory measurements, L. Reinert (EDYTEM) for the BET measurements and E. Zimmermann for his impedance meter. We thank the Editor and two anonymous referees for their useful reviews. AR thanks the GO to have shown him the path.

\section{REFERENCES}

Aran, D., Maul, A. \& Masfaraud, J., 2008. A spectrophotometric measurement of soil cation exchange capacity based on cobaltihexamine chloride absorbance, C.R. Geosci., 340(12), 865-871.

Archie, G.E., 1942. The electrical resistivity $\log$ as an aid in determining some reservoir characteristics, Trans. AIME, 146, 54-62.

Browne, P.R.L., 1978. Hydrothermal alteration in active geothermal fields, Ann. Rev. Earth Planet. Sci., 6, 229-250.

Brunauer, S., Emmett, P.H. \& Teller, E., 1938. Adsorption of gasses in multimolecular layers, J. Am. Chem. Soc., 60(2), 309-319.

Evans, S.R., 1992. Summary geological report and index log of the scientific observation hole \#2 on the Kilauea Rift zone, Hawai 'i, Geotherm. Resour. Council Trans., 16, 157-166.

Frolova, J.V., Ladygin, V.M. \& Rychagov, S.N., 2010. Petrophysical alteration of volcanic rocks in hydrothermal systems of the Kuril-Kamchatka Island arc, in Proceedings World Geothermal Congress, Bali, Indonesia, 25-29 April 2010, 7pp.

Ghorbani, A., Revil, A., Coperey, A., Soueid Ahmed, A., Roque, S., Heap, M.J., Grandis, H. \& Viveiros, F., 2018. Complex conductivity of volcanic rocks and the geophysical mapping of alteration in volcanoes, J. of Volcanology and Geothermal Res., 357, 106-127, doi.org/10.1016/j.jvolgeores.2018.04.014.

Gross, L., Soueid Ahmed, A. \& Revil, A., 2021. Induced polarization of volcanic rocks. 4. Large-scale induced polarization imaging, Geophys. J. Int., doi:10.1093/gii/ggab018, in press.

Kauahikaua, J.P. \& Mattice, M.D., 1981. Geophysical reconnaissance of prospective geothermal areas on the island of Hawai'i using clcctrical methods, U.S. Geological Survey Open-File Report, 50, 81-1044.

Kristmannsdóttir, H., 1979. Alteration of basaltic rocks by hydrothermal activity at $100-300^{\circ} \mathrm{C}$, in International Clay Conference 1978, pp 359367, eds Mortland, M.M. \& Farmer, V.C., Elsevier Scientific Publishing Co.

Misra, S., Torres-Verdín, C., Revil, A., Rasmus, J. \& Homan, D., $2016 \mathrm{a}$. Interfacial polarization of disseminated conductive minerals in absence of redox-active species. Part 1: Mechanistic model and validation, Geophysics, 81(2), E139-E157.

Misra, S., Torres-Verdín, C., Revil, A., Rasmus, J. \& Homan, D., 2016 b. Interfacial polarization of disseminated conductive minerals in absence of redox-active species. Part 2. Effective complex conductivity and dielectric permittivity, Geophysics, 81(2), E159-E176.

Neal, C.A. \& Lockwood, J.P., 2003. Geologic Map of the Summit Region of Kilauea Volcano, Hawaii, Geologic Investigation Series I-2759, U.S. Geolgical Survey, 1 sheet.

Nowack, E.A. \& Evans, S.R., 1991. SOH-2 well, Visual Core Description, Scientific Observation Hole Project, Vol. 2, 238pp., Vol. 3, 95 pp.

Oldenburg, D.W. \& Li, Y., 1994. Inversion of induced polarization data, Geophysics, 59(9), 1327-1341.

Olhoeft, G.R., 1985. Low-frequency electrical properties, Geophysics, 50, 2492-2503.

Pelton, W.H., Ward, S.H., Hallof, P.G., Sill, W.R. \& Nelson, P.H., 1978. Mineral discrimination and removal of inductive coupling with multifrequency IP, Geophysics, 43, 588-609. 
Qi, Y., El-Kaliouby, H., Revil, A., Soueid Ahmed, A., Ghorbani, A. \& Li, J., 2019. Three-dimensional modeling of frequency- and time-domain electromagnetic methods with induced polarization effects, Computers \& Geosciences, 124(3), 85-92.

Qi, Y., Soueid Ahmed, A., Revil, A., Ghorbani, A., Abdulsamad, F., Florsch, N. \& Bonnenfant, J., 2018. Induced polarization response of porous media with metallic particles-Part 7: Detection and quantification of buried slag heaps, Geophysics, 83, E277-E291.

Revil, A., 2013. Effective conductivity and permittivity of unsaturated porous materials in the frequency range $1 \mathrm{mHz}-1 \mathrm{GHz}$, Water Resources Research, 49, 306-327, doi:10.1029/2012WR012700.

Revil, A., Abdel Aal, G.Z., Atekwana, E.A., Mao, D. \& Florsch, N., 2015b. Induced polarization response of porous media with metallic particles - Part 2. Comparison with a broad database of experimental data, Geophysics, 80(5), D539-D552.

Revil, A., Cathles, L.M., Losh, S. \& Nunn, J.A., 1998. Electrical conductivity in shaly sands with geophysical applications, J. geophys. Res., 103(B10), 23925-23936.

Revil, A., Florsch, N. \& Mao, D., 2015a. Induced polarization response of porous media with metallic particles - Part 1: a theory for disseminated semiconductors, Geophysics, 80(5), D525-D538.

Revil, A., Ghorbani, A., Gailler, L.S., Gresse, M., Panwar, N. \& Sharma, R., 2018. Electrical conductivity and induced polarization investigations at Kilauea volcano, Hawai'i, J. Volc. Geotherm. Res., 368, 31-50.

Revil, A., Le Breton, M., Niu, Q., Wallin, E., Haskins, E. \& Thomas, D.M., 2017a. Induced polarization of volcanic rocks. 1. Surface versus quadrature conductivity, Geophys. J. Int., 208, 826-844.

Revil, A., Le Breton, M., Niu, Q., Wallin, E., Haskins, E. \& Thomas, D.M., $2017 \mathrm{~b}$. Induced polarization of volcanic rocks. 2. Influence of pore size and permeability, Geophys. J. Int., 208, 814-825.

Revil, A., Qi, Y., Ghorbani, A., Coperey, A., Soueid Ahmed, A., Finizola, A. \& Ricci, T., 2019. Induced polarization of volcanic rocks. 3. Imaging clay cap properties in geothermal fields, Geophys. J. Int., 218(2), 1398-1427.
Revil, A. et al., 2017c. Complex conductivity of soils, Water Resour. Res., 53, doi:10.1002/2017WR020655.

Seigel, H.O., 1959. Mathematical formulation and type curves for induced polarization, Geophysics, 24(3), 547-565.

Swanson, D.A., Fiske, R.S., Thornber, C.R. \& Poland, M.P., 2018. Dikes in the Koa'e fault system, and the Koa'e-east rift zone structural grain at Kîlauea Volcano, Hawai'i, in Field Volcanology: A Tribute to the Distinguished Career of Don Swanson: Geological Society of America Special Paper 538, pp. 247-274, eds Poland, M.P., Garcia, M.O., Camp, V.E. \& Grunder, A., Geological Society of America.

Taylor, M., Elliott, H.E. \& Navitsky, L.O., 2018. Relationship between total dissolved solids and electrical conductivity in Marcellus hydraulic fracturing fluids, Water Sci. Technol., 77(7-8), 1998-2004.

Tilling, R.I. \& Jones, B.F., 1996. Waters associated with an active basaltic volcano, Kilauea, Hawaii: Variation in solute sources, 1973-1991, Bull. geol. Soc. Am., 108(5), 562-577.

Van Voorhis, G.D., Nelson, P.H. \& Drake, T.L., 1973. Complex resistivity spectra of porphyry copper mineralization, Geophysics, 38(1), 49-60.

Vinegar, H.J. \& Waxman, M.H., 1984. Induced polarization of shaly sands, Geophysics, 49(8), 1267-1287.

Waxman, M.H. \& Smits, L.J.M., 1968. Electrical conductivities in oilbearing shaly sands, SPE J., 8, 107-122.

Wong, J., 1979. An electrochemical model of the induced polarization phenomenon in disseminated sulfide ores, Geophysics, 44, 1245-1265.

Zimmermann, E., Kemna, A., Berwix, J., Glaas, W., Münch, H.M. \& Huisman, J.A., 2008. A high-accuracy impedance spectrometer for measuring sediments with low polarizability. Meas. Sci. Technol., 19(10), 105603, doi:10.1088/0957-0233/19/10/105603.

Árnason, K., Már Vilhjálmsson, A. \& Björnsdóttir, T., 2010. A Study of the Krafla vocano using gravity micro-earthquake and MT data, in Presented at Short Course V on Exploration for Geothermal Resources, organized by UNU-GTP, GDC and KenGen, at Lake Bogoria and Lake Naivasha, Kenya, October 29-November 19, 2010. 